\title{
Alcohol-related breast cancer in postmenopausal women - effect of CYP19A1, PPARG and PPARGC1A polymorphisms on female sex-hormone levels and interaction with alcohol consumption and NSAID usage in a nested case-control study and a randomised controlled trial
}

Tine Iskov Kopp ${ }^{1,2,3^{*}}$, Ditte Marie Jensen ${ }^{2,4}$, Gitte Ravn-Haren ${ }^{1}$, Arieh Cohen ${ }^{5}$, Helle Molgaard Sommer ${ }^{1}$, Lars Ove Dragsted $^{6}$, Anne Tjonneland ${ }^{2}$, David Michael Hougaard ${ }^{5}$ and Ulla Vogel ${ }^{7}$

\begin{abstract}
Background: Alcohol consumption is associated with increased risk of breast cancer (BC), and the underlying mechanism is thought to be sex-hormone driven. In vitro and observational studies suggest a mechanism involving peroxisome proliferator-activated receptor gamma (PPARY) in a complex with peroxisome proliferator-activated receptor gamma coactivator 1-a (PGC-1a) and interaction with aromatase (encoded by CYP19A1). Use of non-steroidal anti-inflammatory drugs (NSAID) may also affect circulating sex-hormone levels by modifying PPARY activity.

Methods: In the present study we assessed whether genetic variation in CYP19A1 is associated with risk of BC in a case-control study group nested within the Danish "Diet, Cancer and Health" cohort ( $\mathrm{n}_{\text {cases }}=687$ and $\mathrm{n}_{\text {controls }}=687$ ) and searched for gene-gene interaction between CYP19A1 and PPARGC1A, and CYP19A1 and PPARG, and gene-alcohol and gene-NSAID interactions. Association between the CYP19A1 polymorphisms and hormone levels was also examined among 339 non-HRT users. Incidence rate ratios were calculated based on Cox' proportional hazards model. Furthermore, we performed a pilot randomised controlled trial to determine the effect of the PPARG Pro ${ }^{12}$ Ala polymorphism and the PPARY stimulator Ibuprofen on sex-hormone levels following alcohol intake in postmenopausal women $(n=25)$ using linear regression.

(Continued on next page)
\end{abstract}

\footnotetext{
* Correspondence: tine.iskov.kopp@regionh.dk

${ }^{1}$ Technical University of Denmark, National Food Institute, Søborg, Denmark

2Danish Cancer Society Research Center, Copenhagen, Denmark

Full list of author information is available at the end of the article
} 
(Continued from previous page)

Results: Genetic variations in CYP19A1 were associated with hormone levels (estrone: $P_{\text {rs } 11070844}=0.009$, estrone sulphate: $P_{\text {rs } 11070844}=0.01, P_{\text {rs } 749292}=0.004, P_{\text {rs } 1062033}=0.007$ and $P_{\text {rs } 10519297}=0.03$, and sex hormone-binding globulin $(\mathrm{SHBG}): P_{\mathrm{rs} 3751591}=0.03$ ) and interacted with alcohol intake in relation to hormone levels (estrone sulphate:

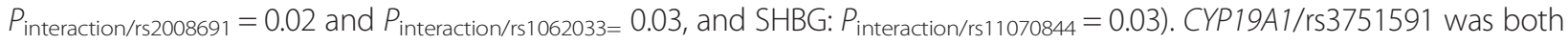
associated with SHBG levels $(P=0.03$ ) and with risk of BC (Incidence Rate Ratio $=2.12 ; 95 \%$ Confidence Interval: 1.02-4.43) such that homozygous variant allele carriers had increased levels of serum SHBG and were at increased risk of $B C$. Acute intake of alcohol decreased blood estrone $(P=<0.0001)$, estrone sulphate $(P=<0.0001)$, and SHBG $(P=0.009)$ levels, whereas Ibuprofen intake and PPARG Pro ${ }^{12}$ Ala genotype had no effect on hormone levels.

Conclusions: Our results suggest that genetically determined variation in CYP19A1 is associated with differences in sex hormone levels. However, the genetically determined differences in sex hormone levels were not convincingly associated with $\mathrm{BC}$ risk. The results therefore indicate that the genetically determined variation in CYP19A1 contributes little to $B C$ risk and to alcohol-mediated BC risk.

Trial registration: NCT02463383, June 3, 2015.

Keywords: Alcohol consumption, Breast cancer, Polymorphisms, CYP19A1, PPARG, Female sex-hormones, NSAID, Prospective nested case-control study, Epidemiology, Randomised controlled trial

\section{Background}

Alcohol is a well-known risk factor for breast cancer (BC) [1-3], and observational studies have shown that intake of alcohol is associated with 7-10 \% increased risk of $\mathrm{BC}$ per $10 \mathrm{~g}$ alcohol consumed per day (defined as a unit of alcohol by the World Health Organisation) [4-9]. It is believed that at least part of the underlying mechanism is sex-hormone driven $[1,10,11]$. Several controlled experimental and observational human studies demonstrate associations between alcohol intake and increased female sex-hormone blood concentrations in pre- and postmenopausal women [12-25]. Additionally, alcohol is more strongly associated to hormone-sensitive BCs than hormone-insensitive subtypes [26]. Increased aromatization [27, 28], impairment of estrogen metabolism in the liver [27] or stimulation of adrenal steroidogenesis [17] are possible mechanisms by which alcohol increases sex-hormone concentrations in women.

Genetic epidemiology in BC research may be used to elucidate the involved molecular pathways and define subpopulations of women being more susceptible to alcohol-related BC risk. Indeed, in the Danish prospective cohort study "Diet, Cancer and Health" (DCH), variant allele carriers of the PPARG2 Pro ${ }^{12}$ Ala (rs1801282) polymorphism had a $20 \%$ increased risk of $\mathrm{BC}$ per $10 \mathrm{~g}$ of alcohol consumed per day, whereas carriage of the wild type allele was not associated with alcohol-related BC [29], thus implicating peroxisome proliferator-activated receptor gamma (PPAR $\gamma$ ) in alcohol-related breast carcinogenesis. In an updated study including $798 \mathrm{BC}$ cases, the risk estimate was $13 \%$ increased risk per $10 \mathrm{~g}$ alcohol per day among variant allele carriers [30].

PPARY is a transcription factor which regulates adipocyte differentiation and expression of several adipocyte specific genes by binding to regulatory response elements in target genes as a heterodimer with retinoid $\mathrm{X}$ receptor (RXR) [31]. The Pro to Ala substitution caused by the single nucleotide polymorphism (SNP), PPARG2 Pro ${ }^{12} \mathrm{Ala}$, is only present in PPAR $\gamma 2$ isoform, which is primarily expressed in adipose tissue [31]. The PPARG2 Pro ${ }^{12}$ Ala substitution causes a $30 \%$ reduction in target gene transcription [32]. In postmenopausal women, estrogens are primarily synthesized in adipose tissue, where aromatase (encoded by CYP19A1) catalyses the biosynthesis of estrogens [33]. Intake of alcohol increases aromatase expression in fat tissue in rats [34], and aromatase is negatively regulated by PPAR $\gamma$ at the transcriptional level $[35,36]$ by a mechanism involving binding of the PPAR $\gamma$-RXR complex to peroxisome proliferator-activated receptor gamma coactivator $1-\alpha$ $(\mathrm{PGC}-1 \alpha)$ [37]. An in vitro study has shown that ethanol inhibits the PPAR $\gamma$-PGC- $1 \alpha$ complex at physiologically relevant concentrations [30]. Moreover, Petersen et al. also showed that PGC- $1 \alpha$ dependent co-activation of the PPAR $\gamma$-complex is compromised for the rare Ala-variant of PPARG Pro ${ }^{12}$ Ala. Thus, it was proposed that alcohol inhibits PPAR $\gamma$-mediated inhibition of aromatase transcription, resulting in an alcohol and PPAR $\gamma$-dependent increased aromatase transcription and increased levels of sex-hormones.

Several commonly used non-steroidal anti-inflammatory drugs (NSAIDs) including ibuprofen are PPARY agonists [38]. Indeed, some NSAIDs are suspected to function as endocrine disruptors $[39,40]$. In the DCH cohort study, interaction between use of NSAIDs and the PPARG Pro ${ }^{12}$ Ala polymorphism in relation to alcohol-related risk of BC was observed [29]. NSAID use did not modify the risk of alcohol-related $\mathrm{BC}$ among PPARG $\mathrm{Pro}^{12} \mathrm{Ala}$ wild 
type carriers, however, among variant carriers, only users of NSAIDs were at risk of alcohol-related BC. Thus, the study indicated that NSAIDs activate the less active PPAR $\gamma{ }^{12} \mathrm{Ala}$ variant so that it has the same effect as the wild type PPARy $\mathrm{Pro}^{12}$ transcription factor. In a metaanalysis, NSAIDs use has been associated with lowered risk of $\mathrm{BC}$ [41]. However, in the $\mathrm{DCH}$ cohort, female NSAID users, with an intake of more than $13 \mathrm{~g}$ alcohol per day had a 1.60 fold increased risk of BC compared to non-users of NSAIDs who consumed less than $3 \mathrm{~g}$ of alcohol per day [42], indicating that alcohol consumption modifies BC risk among NSAID users.

In the present study we further pursue the proposed mechanism of action of alcohol-related BC. We assess whether genetic variation in CYP19A1 is associated with risk of $\mathrm{BC}$ in a case-control study group nested within the $\mathrm{DCH}$ cohort; and search for gene-gene interactions with CYP19A1 and PPARGC1A, and CYP19A1 and $P P A R G$, and gene-alcohol and gene-NSAID interactions (interactions between PPARG and PPARGC1A were examined and published previously [30]). Association between the CYP19A1 polymorphisms and hormone levels is also examined in a cross-sectional study based on the nested case-control study. Furthermore, we perform a pilot randomised controlled trial (RCT) to determine the effect of PPARG Pro ${ }^{12} \mathrm{Ala}$ and the PPARY stimulator, Ibuprofen [38], on sex-hormone levels following alcohol intake in postmenopausal women.

\section{Methods}

\section{DHC cohort study}

\section{Participants}

The subjects were selected from the ongoing Danish DCH cohort study. The present study group has been described previously $[8,30]$. In short, 79,729 women aged 50-64 years, born in Denmark, living in the Copenhagen or Aarhus areas and having no previous cancers at the time of invitation were invited to participate in the study between December 1993 and May 1997. A total of 29,875 women accepted the invitation, corresponding to $37 \%$ of the invited women.

Study participants were followed up for diagnosis of $\mathrm{BC}$ from date of entry until either the date of diagnosis of cancer using record linkage to the Danish Cancer Registry until 2003 and afterwards by linkage to the Danish Pathology Databank, date of death, date of emigration, or April 27th, 2006, whichever came first. A total of 975 women were diagnosed with $\mathrm{BC}$ during the follow-up period. For each case, one matched control was selected $[8$, 30, 43]. The control was cancer-free at the exact age at diagnosis of the case and was further matched on age at inclusion into the cohort (half-year intervals), use of hormone replacement therapy (HRT) (current/former/never) and on certainty of postmenopausal status (known/probably postmenopausal) upon inclusion into the cohort. "Known" postmenopausal status was defined as women that were either: (1) non-hysterectomized and reporting no menstruation during 12 months before inclusion, (2) reporting bilateral oophorectomy, or (3) reporting age at last menstruation lower than age at hysterectomy. "Probably" postmenopausal status was defined as women that were either: (1) reporting menstruation during the 12 months prior to inclusion and current use of HRT (we assumed the bleeding was caused by HRT), (2) reporting hysterectomy with a unilateral oophorectomy or an oophorectomy of unknown laterality, or (3) reporting last menstruation at the same age as age of the hysterectomy operation [8]. 72 individuals were excluded because of missing information about one or more of the potential confounding variables. Additionally 239 individuals were excluded because of failed genotyping or no buffy coat was available. 265 individuals were excluded because of a missing partner in the matched case-control pair, due to the above mentioned exclusions leaving 687 pairs for data analyses (Fig. 1).

Levels of estrone, estrone sulphate and SHBG were previously determined for a subset of the $\mathrm{DCH}$ study (434 cases and controls) in plasma samples collected at entry into the cohort - a cross-sectional study [44]. Of these 434 cases and controls, 8 had extreme hormone measures, 117 had missing values on hormone analyses, genotypes or confounder information, and 404 were present users of HRT resulting in 339 women for these analyses.

\section{Data on covariates}

From the baseline questionnaires we obtained information on duration of school education, smoking status, HRT use, birth pattern (number of births and age at first birth) and alcohol intake. Body Mass Index (BMI) was computed based on measurements of height and weight at enrolment $\left(\mathrm{kg} / \mathrm{m}^{2}\right)$. Intake of alcohol was inferred from the food-frequency questionnaire and life-style questionnaire as described in details in $[8,30]$. Abstainers were defined as those who reported no intake of alcohol on the food-frequency questionnaire and no drinking occasions on the lifestyle questionnaire. The lifestyle questionnaire included this question regarding use of NSAID: Have you taken more than one pain relieving pill per month during the last year? If the answer was yes, the participant was asked to record how frequent they took each of the following medications: 'aspirin,',paracetamol,' 'ibuprofen', or 'other pain relievers'. The latter category included NSAID preparations other than aspirin and ibuprofen. Based on all records, we classified study subjects according to use of 'any NSAID' ( $\geq 2$ pills per month during one year) at baseline. Findings on all of these known risk factors have been reported previously for 


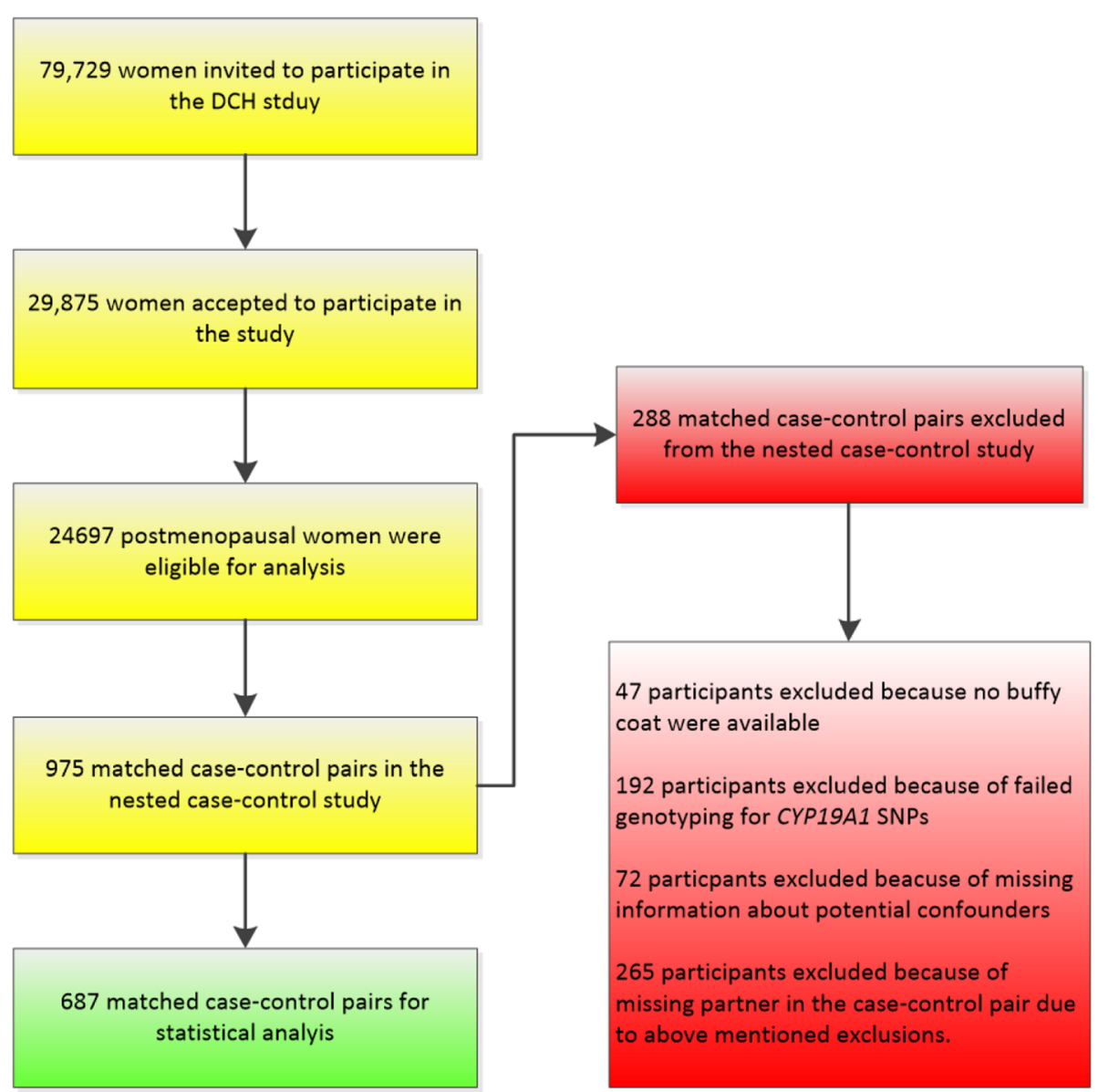

Fig. 1 Flow chart illustrating inclusion and exclusions of participants in the nested case-control postmenopausal DCH study

both the entire $\mathrm{DCH}$ cohort, for a subset of the present study, and for the present study group [5, 8, 29, 42, 45, 46].

\section{Ethics statement}

All participants gave verbal and written informed consent before enrolment to the study. The Diet, Cancer and Health study was approved by the National Committee on Health Research Ethics (journal nr. (KF) 01-345/93), and the Danish Data Protection Agency.

\section{RCT}

\section{Participants}

The RCT was conducted at the Department of Nutrition, Exercise and Sports, University of Copenhagen, Denmark. The participants were recruited by advertisements in the Copenhagen area, in local newspapers and at the webpage www.forsogsperson.dk. To be eligible, women had to meet the following requirements: 1) aged 50-70 years and postmenopausal (last menstruation at least 1 year earlier); 2) having no history of hysterectomy before last menstruation with preservation of both ovaries (unless a medical confirmation for the postmenopausal status exists or the participant is 60 years or older); 3) having no major health problems, such as ulcers, heart diseases, diabetes or cancer; 4) having a weekly alcohol use of less than 14 drinks, but not being an abstainer and having no history of alcohol abuse; 5) not using HRT; 6) not taking prescription medications that could interfere with the study (i.e. daily use of NSAIDs and/or medication that interact with PPAR $\gamma$ e.g. cholesterol lowering medicine); 7) having a BMI of $18-35$; 8) not being allergic to alcohol and/or Ibuprofen; 9) being a non-smoker.

Power calculation showed that there was an $80 \%$ chance of finding a $10 \%$ change in estradiol level if 11 participants were included in each group $(\alpha=5 \%)$. In order to take drop out into account, we decided to enrol 18 women in each group. However, only 7 (16 \%) women were $P P A R G{ }^{12} \mathrm{Ala}$ carriers, and they were all included in the study as well as 18 homozygous wild type carriers of the PPARG Pro $^{12}$ allele.

\section{Study design}

The study was performed as a randomised, doubleblinded, placebo controlled $2 \times 24 \mathrm{~h}$ crossover study as 
illustrated in Fig. 2. The two interventions were separated by a $5-7$ week washout period. Alcohol was supplied as $96 \%$ ethanol (Navimer, G.D.C., Jumet, Belgium) in an $8 \%$ solution with 1:8 Rose's Lime Flavour Cordial Mixer $^{\circ}$ (Dr Pepper Snapple Group Inc., Plano, Texas), 1:8 Rose's Sugar Cane Flavour Cordial Mixer ${ }^{\circledR}$ (Dr Pepper Snapple Group Inc., Plano, Texas) and water $(0.4 \mathrm{~g}$ ethanol/kg b.w.). Placebo and Ibuprofen tablets looked identical. Placebo tablets were supplied by The Pharmacy of the Capital Region of Denmark (Herlev, Denmark), and Ibuprofen (2 x $200 \mathrm{mg})$ by Nycomed ApS (Roskilde, Denmark).
Forty-eight hours before each intervention, participants were asked to refrain from alcohol consumption and any form of painkillers. The participants showed up fasting and were served lunch at the University's dining facility $1 \frac{1}{2}$ hour before drinking (Fig. 3). The lunch consisted of a sandwich, which was identical for each participant at each intervention, and was eaten within $30 \mathrm{~min}$. All blood samples were collected following $10 \mathrm{~min}$ supine resting. The first blood sample was drawn $40 \mathrm{~min}$ before serving the drink. Just after this blood collection and $30 \mathrm{~min}$ prior to drinking, participants had their Ibuprofen or placebo tablet administered. This time point was chosen in order to

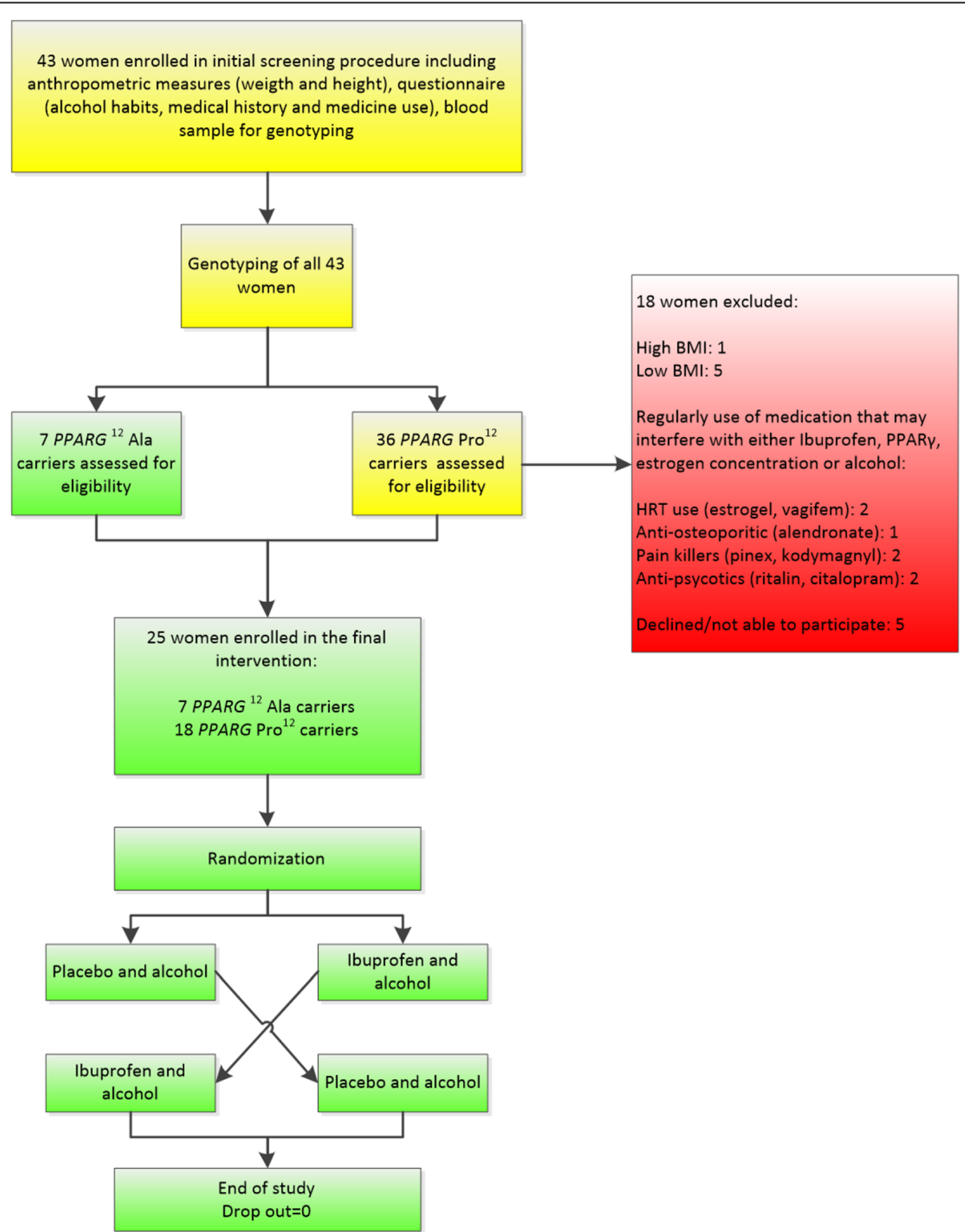

Fig. 2 Flow chart illustrating inclusion and exclusions of participants in the RCT performed as a randomised, double-blinded, placebo controlled $2 \times 24$ h crossover study 


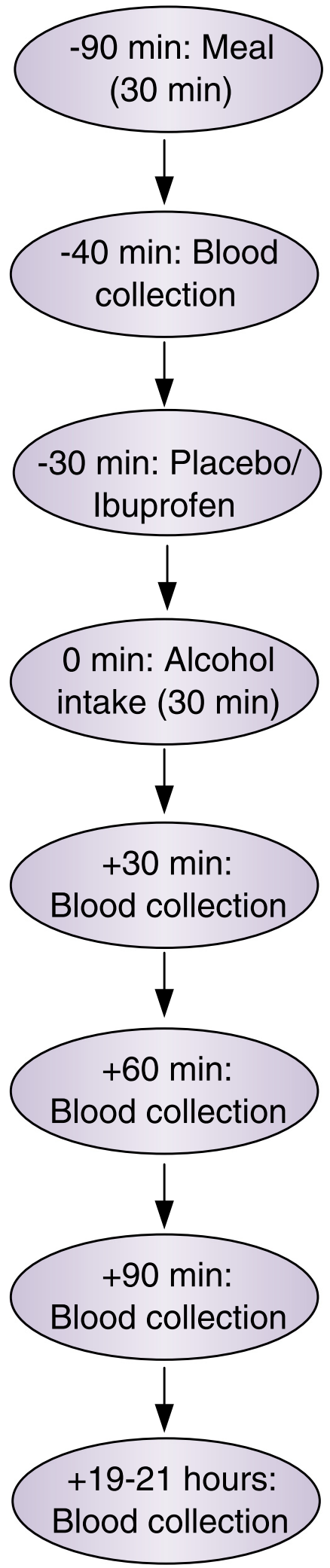

Fig. 3 The study course for each participant at each intervention in the RCT. The intervention was repeated with or without Ibuprofen resulting in two interventions per participant capture the plasma concentration peak of Ibuprofen which is $1-2 \mathrm{~h}$ after administration [47, 48]. After another $30 \mathrm{~min}$, the alcoholic beverage was administered and consumed within 30 min under the surveillance of a research assistant to ensure that the drink was ingested slowly over the entire period. After 30, 60 and 90 min, blood was collected. These time points were selected based on two other studies reporting peak in blood estradiol concentrations between 30 and 60 min after alcohol consumption $[16,20]$. The next morning, the participants showed up again for the last blood collection. This time point was chosen to enable the comparison of our results with those obtained in long term intervention or cohort studies where blood typically is collected the day after having consumed alcohol. Since estrone sulphate has a half-life of 5$7 \mathrm{~h}$ [17], an alcohol induced change in estrone sulphate caused by disruption in estrogen biosynthesis would be measurable in this morning blood sample.

\section{Blood sampling and storage}

For the genotype screening, blood was collected in $6 \mathrm{ml}$ EDTA BD Vacutainer Blood Collection Tubes (Becton, Dickinson and Company) and buffy coat was separated by centrifugation $\left(4000 \mathrm{rpm}, 4{ }^{\circ} \mathrm{C}\right)$ and frozen at $-80{ }^{\circ} \mathrm{C}$. During the intervention, blood was collected in $10 \mathrm{ml}$ silicone-coated serum BD Vacutainer ${ }^{\circledR}$ Blood Collection Tubes (Becton, Dickinson and Company) for ethanol and hormone measurements. The tubes were left at room temperature for $>30 \mathrm{~min}$, centrifuged $\left(4000 \mathrm{rpm}, 4{ }^{\circ} \mathrm{C}\right)$ and aliquots were frozen at $-80^{\circ} \mathrm{C}$. To avoid ethanol evaporation from the tubes during storage, serum for ethanol analysis was kept in tubes with airtight caps.

\section{Ethics statement}

The research protocol was approved by The National Committee on Health Research Ethics for the Capital Region of Denmark, protocol number: H-3-2013-056. All participants received oral and written information concerning the study before giving their written consent.

\section{Laboratory methods \\ DCH cohort study}

DNA from the DCH participants was extracted from frozen lymphocytes as described [49]. PPARG Pro $^{12} \mathrm{Ala}$ (rs1801282), PPARGC1A Gly ${ }^{482}$ Ser (rs8192678) and PPARGC1A $\mathrm{Thr}^{612}$ Met (rs3736265) were determined as previously described [30] and have been published previously $[29,30]$. Ten tagging SNPs of the CYP19A1 gene were selected using publicly available HapMap [50] genotyping data set from Utah residents with ancestry from Northern and Western Europe (CEU, version 3, release 2) in combination with Haploview (version 4.2, Broad Institute, Cambridge USA) [51] comprising the major variations in CYP19A1. Criteria for SNP inclusions 
were a minor allele frequency of minimum $5 \%$ and an $\mathrm{r}^{2}$ threshold of 0.1. Tagging of SNPs with an $\mathrm{r}^{2}$ higher than 0.1 resulted in several SNPs being in complete linkage disequilibrium. Moreover, our intention was to include only major polymorphisms in the gene. Four polymorphisms were force included in the aggressive SNP tagging (rs10046, rs749292, rs1062033 and rs10519297) due to their documented effect on aromatase RNA expression, blood hormone levels and/or BC risk [11, 52-59]. Moreover, one of the tag SNPs (rs4646) has been associated with BC [59] and blood estrogen levels [53, 56, 60]; another tag SNP (rs2445762) was associated with low estradiol levels in GWAS [61]; and rs3751591 is located in a recombination spot between two haplotype blocks (Additional file 1).

Four of the polymorphisms (rs10046, rs749292, rs1062033 and rs10519297) were determined using the ABI 7900HT RT-PCR system (Applied Biosystems, Nærum, Denmark): rs10046 and rs1062033 were determined using the TaqMan ${ }^{\circ}$ Pre-designed SNP genotyping; assay ID C_8234732_30 and C_8794680_30, respectively (Applied Biosystems, Nærum, Denmark). rs749292: Primers: F: 5'-GCT TCT GCC AGT CCT TCT TCA-3, R: 5'-GCT TAG GGC CTG ATA GAA ATT GTG-3' (TAGCopenhagen, Copenhagen, Denmark), G-allele: 5'-FAM-CTC GGA GTC GAG GAT-MGB-3', A-allele: 5'-VIC-TCG GAG TCA AGG ATT-MGB-3' (Applied Biosystems, Nærum, Denmark). rs10519297: Primers: F: 5'CCT TGC CTG AGC CAT CTC TT-3', R: 5'- CTT GGC AGT CAA AAG CAG TAG TAG TC-3' (TAGCopenhagen, Copenhagen, Denmark), G-allele: 5'-FAMCTC CGA CAT GGG TC-MGB-3', A-allele: 5'-VIC-TCT CCG ACA TAG GTC-MGB-3' (Applied Biosystems, Nærum, Denmark).

The remaining six CYP19A1 polymorphisms (rs2008691, rs2445762, rs3751591, rs4646, rs6493487 and rs749292) were genotyped by KBioscience (KBioscience, Hoddesdon, United Kingdom) by PCR-based KASP ${ }^{\mathrm{rm}}$ genotyping assay (http://www.lgcgenomics.com/). To confirm reproducibility, genotyping was repeated for $10 \%$ of the samples yielding $100 \%$ identical genotypes.

Serum levels of estrone, estrone sulphate and sexhormone binding globulin (SHBG) were previously determined for a subset of the DCH study (434 cases and controls) in blood samples collected at entry into the DCH cohort [44]. Estrone and estrone sulphate were measured by radioimmunoassay and SHBG by use of immunofluorometric analysis.

\section{RCT}

DNA was isolated from frozen lymphocytes as described by Miller et al. [49]. Genotypes were determined using RT-PCR and allelic discrimination on ABI 7900HT instruments (Applied Biosystems, Nærum, Denmark).
Generally, 40-200 ng/ $\mu \mathrm{l}$ DNA was obtained and $10 \mathrm{ng}$ of DNA was genotyped in five $\mu$ l containing $50 \% 2 \times$ Mastermix (Applied Biosystems, Nærum, Denmark), $100 \mathrm{nM}$ probes, and $900 \mathrm{nM}$ primers. PPARG Pro ${ }^{12} \mathrm{Ala}$ (rs1801282) primers and probes were: primers: 5'-GTT ATG GGT GAA ACT CTG GGA GAT-3' and 5'-GTT ATG GGT GAA ACT CTG GGA GAT-3': probes: Callele: 5"-FAM-CTC CTA TTG ACG CAG AAA GCG ATT C-BHQ-1-3' and G-allele: 5'-Yakima Yellow-TCC TAT TGA CCC AGA AAG CGA TTC C-BHQ-1-3'. Serum ethanol concentration was measured by the enzymatic rate assay (kat. no. 11776312190, Roche Diagnostics GmbH, Mannheim, Germany) using the ABX Pentra 400 (Horiba Medical, Brøndby, Denmark) instrument with inter- and intra assay variations of $<4 \%$. All samples from each participant were analysed in duplicates in random order and in the same batch to decrease analytical variation.

Analyses of estrogens and SHBG levels were performed at the Department of Clinical Biochemistry and Immunology, Statens Serum Institute, Copenhagen, Denmark. Estrogens were extracted by Solid-Phase Extraction and the extracts were analyzed using LiquidChromatography (LC) coupled to Mass-Spectrometry (MS). All samples were analyzed in duplicate and the average of both measurements was used. Within the working range of the method $(20 \mathrm{pmol} / \mathrm{L}$ to $50 \mathrm{nmol} / \mathrm{L})$ the coefficient of variation $(\mathrm{CV})$ for all analytes were $10 \%$ for estrone, estrone sulphate and $17 \beta$-estradiol and the CV's increased below the working range and reached $20 \%$ at the limit of quantification (LOQ) $(10 \mathrm{pmol} / \mathrm{L}) .60 \%$ of the estradiol analyses were below the limit of detection (LOD) $(1 \mathrm{pmol} / \mathrm{L})$; therefore, these measurements were excluded from statistical analyses. SHBG was determined on an Abbott Architect using Abbotts SHBG kit (Abbott, Abbott Park, Illinois). The LOD and the intra- and interassay $\mathrm{CV}$ were $0.1 \mathrm{nmol} / \mathrm{l}, 4$ and $6 \%$, respectively.

\section{Statistical methods \\ DCH cohort study}

Deviation from Hardy-Weinberg equilibrium was assessed using a Chi square test.

The analysis of the association between the exposure variables and the $\mathrm{BC}$ incidence rate ratios (IRR) was based on a conditional logistic regression analysis corresponding to a Cox Proportional Hazard model due to the used study design [62]. Age was used as the time axis. Two-sided $95 \%$ confidence intervals $(\mathrm{CI})$ for the IRR were calculated on the basis of Wald's test of the regression parameter, that is, on the log rate ratio scale. All models were adjusted for baseline values of risk factors for BC such as parity (entered as two variables; parous/ nulliparous and number of births), age at first birth, length of school education (low, medium and high), duration of 
HRT use, and BMI. Analyses not concerning interaction between alcohol intake and the polymorphisms were further adjusted for alcohol intake of $10 \mathrm{~g}$ per day. For the different genetic variations, we investigated different interactions with alcohol intake and use of NSAID, using the likelihood ratio test. IRR was calculated separately for heterozygous and homozygous variant allele carriers. For all the SNPs except for rs3751591, all variant allele carriers were subsequently grouped for interaction analyses since no recessive effects were observed. For rs3751591, a recessive mode was used in the subsequent analyses. Haplotypes of CYP19A1 were inferred manually as done previously [63-65].

For the analyses with sex-hormone levels as outcome, multiple log-linear regression analyses of the association between CYP19A1 genotypes and serum levels of estrone, estrone sulphate and SHBG were performed with adjustment for potential confounders i.e., age (linear), smoking (categorical: never, past and current) and BMI (linear). All interaction terms were kept in the models in all analyses even though there was no interaction for comparison. All values of hormone concentrations were log-transformed to correct for left-skewed distribution. The statistical analyses were carried out using the PHREG and GLM procedure in SAS (release 9.3, SAS Institute, Inc, Cary, North Carolina, USA).

\section{$R C T$}

Linear regression was used to evaluate the effect on PPARG Pro ${ }^{12}$ Ala genotype status and treatment of Ibuprofen during consumption of alcohol.

Two different models were used to analyse the data due to non-linear responses with time over the whole period (0 to $1200 \mathrm{~min}$ ). Model A only involved the time at the beginning of the trial period and the end (time $=0$ and time $=1200 \mathrm{~min}$ ), whereas model $\mathrm{B}$ involved the times 0, 30, 60, and 90 min after start. Model A used the PROC MIXED procedure in SAS with id as the random effect nested with genotype and order (geno*order). The explanatory categorical variables were treatment with Ibuprofen and placebo (treat), order in which they were given Ibuprofen or placebo (order), genotype (geno), and time (0 and 1200). BMI was included as a covariate.

Model $\mathrm{B}$ also used the PROC MIXED procedure in SAS with id as the random effect nested with genotype and order (geno*order). The explanatory categorical variables were treatment with Ibuprofen or placebo (treat), order in which they were given Ibuprofen and placebo (order), genotype (geno), and time (0, 30, 60, 90). BMI was included as a covariate. Time was also included as repeated measurement with id (geno*treat*order) as the subject.

The response variable, estrone sulphate, was logtransformed to correct for right-skewed distribution.
The response variables estrone, SHBG and ethanol were not log-transformed, since the conditional residuals were not or only very little skewed.

In some of the analyses, one or two outliers were removed if they were very dominating, had high Cook's D value and a relatively large residual value. Zero values of estrone measurements (11\%) were replaced by half of $\mathrm{LOD}=0.5 \mathrm{pmol} / \mathrm{L}$.

The statistical analyses were carried out using SAS (release 9.3, SAS Institute, Inc, Cary, North Carolina, USA). For all tests, a $P$ value less than 0.05 was considered statistically significant.

\section{Results}

\section{DCH cohort study}

Baseline characteristics of the present study group including $\mathrm{BC}$ risk factors are presented in Table 1 as published previously $[8,30]$. Among the controls, the genotype distributions of the studied polymorphisms were in Hardy-Weinberg equilibrium (results not shown).

\section{Associations with hormone levels}

The cross-sectional study group including 339 women from the matched case-control study was used for this analysis. Among past and never users of HRT, the hormone levels were associated with genotype of five of the ten studied polymorphisms. Variant T-carriers of the CYP19A1/rs11070844 polymorphism had $17 \%$ higher estrone levels $(P=0.009)$ and $14 \%$ higher estrone sulphate levels $(P=0.01)$ than homozygous wild type allele carriers (Table 2). SHBG levels were $37 \%$ higher among CC-carriers of the CYP19A1/rs3751591 polymorphisms compared to T-carriers $(P=0.03)$. Carriers of the variant alleles of the two CYP19A1 polymorphisms rs749292 and rs1062033 had $12 \%$ lower levels of estrone sulphate compared to homozygous wild type allele carriers $(P=0.004$ and 0.007 , respectively), and variant carriers of the CYP19A1/rs10519297 polymorphism had $12 \%$ higher levels of estrone sulphate compared to the wild type $(P=0.03)$. Thus, several of the studied SNPs were associated with hormone levels (Table 2).

Three of the ten CYP19A1 polymorphisms were associated with alcohol-dependent changes in hormone levels according to genotype (Table 3 ). Carriers of the variant alleles of $C Y P 19 A 1 / \mathrm{rs} 2008691$ and $C Y P 19 A 1 / \mathrm{rs} 1062033$ polymorphisms had $3 \%$ and $1 \%$ higher estrone sulphate levels, respectively, compared to homozygous wild type carriers (P-value for interaction $\left(P_{\text {int }}\right)=0.02$ and 0.03, respectively) per $10 \mathrm{~g}$ alcohol intake per day. Variant $\mathrm{T}$ carriers of the CYP19A1/rs11070844 polymorphism had $3 \%$ lower levels of SHBG compared to the wild type carriers $\left(P_{i n t}=0.03\right)$ per $10 \mathrm{~g}$ daily alcohol intake. In general, estrone and estrone sulphate levels increased whereas SHBG levels decreased for every $10 \mathrm{~g}$ alcohol 
Table 1 Baseline characteristics of the DCH study participants by selected demographic and established BC risk factors

\begin{tabular}{|c|c|c|c|c|c|}
\hline \multirow[t]{2}{*}{ Variable } & \multicolumn{2}{|l|}{ Cases } & \multicolumn{2}{|l|}{ Controls } & \multirow[t]{2}{*}{$\mathrm{IRR}^{\mathrm{a}}(95 \% \mathrm{Cl})$} \\
\hline & $n(\%)$ & Median (5-95\%) & $\overline{n(\%)}$ & Median (5-95 \%) & \\
\hline Women & $687(100)$ & & $687(100)$ & & \\
\hline Age at inclusion, years & & $57(51-64)$ & & $57(51-64)$ & \\
\hline \multicolumn{6}{|l|}{ School education } \\
\hline Short & $198(29)$ & & $257(37)$ & & 1.0 (ref.) \\
\hline Medium & $344(50)$ & & $316(46)$ & & $1.39(1.07-1.79)$ \\
\hline Long & $145(21)$ & & $114(17)$ & & $1.59(1.13-2.24)$ \\
\hline Body mass index, $\mathrm{kg} / \mathrm{m}^{2}$ & & $25(20-34)$ & & $25(20-34)$ & $1.01(0.96-1.07)^{\mathrm{b}}$ \\
\hline Nulliparous & $102(15)$ & & $78(11)$ & & $1.02(0.64-1.60)^{c}$ \\
\hline Number of births & & $2(1-4)$ & & $2(1-4)$ & $0.92(0.79-1.06)$ \\
\hline Age at first birth, years & & $23(18-31)$ & & $23(18-32)$ & $1.07(0.91-1.25)^{\mathrm{d}}$ \\
\hline Use of HRT, years ${ }^{\mathrm{e}}$ & & $6(0.5-19)$ & & $5(0.5-20)$ & $1.00(0.87-1.15)^{f}$ \\
\hline Abstainers & $15(2)$ & & $22(3)$ & & $0.80(0.40-1.61)^{9}$ \\
\hline Alcohol intake, g/day & & $11(1-43)$ & & $9(1-40)$ & $1.12(1.04-1.21)^{\mathrm{h}}$ \\
\hline NSAID use ${ }^{i}$ & $286(42)$ & & $239(35)$ & & $1.33(1.07-1.66)$ \\
\hline
\end{tabular}

Values are expressed as medians (5th and 95th percentiles) or as fractions (\%)

${ }^{a}$ The risk estimates for breast cancer are mutually adjusted

${ }^{\mathrm{b}}$ The risk is estimated per additional $2 \mathrm{~kg} / \mathrm{m}^{2}$

'The risk is estimated for nulliparous versus one birth at age 35

${ }^{\mathrm{d}}$ The risk is estimated per additional 5 years

${ }^{\mathrm{e}}$ Among ever users of HRT

${ }^{\mathrm{f}}$ The risk is estimated per additional 5-year of HRT use

${ }^{9}$ The risk for abstainers compared to the increment of $10 \mathrm{~g}$ alcohol per day

${ }^{\mathrm{h}}$ Among drinkers, risk estimate is estimated for the increment of $10 \mathrm{~g}$ alcohol per day

i NSAID use is defined as $\geq 2$ pills per month during one year

consumed per day irrespectively of genotype (Table 3). Estrone sulphate levels differed significantly according to CYP19A1/rs3751591 genotype for NSAID users and nonusers, respectively $\left(P_{\text {int }}=0.008\right)$ (Additional file 2 ). Carriers of the CC genotype had $48 \%$ higher levels of estrone sulphate when using NSAID compared to T-carriers who did not use NSAID (95 \% CI: 3;114), whereas T-allele carriers who were also NSAID users had $13 \%$ decreased levels of estrone sulphate $(95 \% \mathrm{CI} ;-20 ;-5)$. However, these estimates were based on very small numbers. There was also a borderline statistically significant interaction between NSAID usage and the CYP19A1/rs6493487 polymorphism in relation to SHBG levels $\left(P_{i n t}=0.05\right)$. Overall, NSAID users had higher levels of SHBG and lower levels of estrone and estrone sulphate (Additional file 2). Thus, some of the studied CYP19A1 SNPs were associated with hormone levels and a few other SNPs interacted with alcohol intake in relation to hormone levels. CYP19A1/ rs1062033 was associated to both hormone levels and to alcohol-dependent differences in hormone levels.

\section{Associations with $B C$ risk}

Homozygous variant carriers of the CYP19A1/rs3751591 polymorphism were at 2.12-fold increased risk of BC (95\% CI: 1.02-4.43) compared to wild-type carriers (Table 4). Carriers of the haplotype combination GGG/GAG
(CYP19A1/A-rs10046-G, A-rs6493487-G, A-rs10519297-G) were at $56 \%$ increased risk of $\mathrm{BC}(\mathrm{IRR}=1.56 ; 95 \% \mathrm{CI}$ : 1.02-2.40) (Additional file 3). Thus, CYP19A1/rs3751591 was both associated with SHBG levels and with risk of $\mathrm{BC}$ such that homozygous variant allele carriers had higher levels of serum SHBG and were at increased risk of $\mathrm{BC}$.

None of the CYP19A1 polymorphisms interacted with alcohol (Additional file 4) or NSAID usage (Additional file 5) in relation to $B C$ risk. All risk estimates showed increased risk of $\mathrm{BC}$ of $10-66 \%$ per $10 \mathrm{~g}$ alcohol per day regardless of genotype (Additional file 4). NSAID usage also increased $\mathrm{BC}$ risk compared to non-users irrespectively of genotype (Additional file 5). There was no interaction between any of the CYP19A1 polymorphisms and being carrier of either of the PPARG Pro ${ }^{12}$ Ala alleles (Additional file 6). However, we found interaction between CYP19A1/rs3751591 and PPARGC1A Gly ${ }^{482} \mathrm{Ser}$ $\left(P_{\text {int }}=0.02\right)$ in relation to $\mathrm{BC}$ risk (Additional file 7); and interaction between CYP19A1/rs4646 and PPARGC1A $\mathrm{Thr}^{612}$ Met $\left(P_{\text {int }}=0.002\right)$ in relation to BC risk (Additional file 8). Wild type carriers of CYP19A1/rs4646, who were also variant Met-carriers of PPARGC1A $\mathrm{Thr}^{612}$ Met were at 2.06-fold increased risk of BC (95\% CI: 1.17-3.65). Conversely, variant $C Y P 19 A 1 /$ rs4646-carriers, who also carry the variant PPARGC1A $\mathrm{Thr}^{612}$ Met allele had a 
Table 2 Plasma levels of estrone, estrone sulphate and SHBG among 339 never and past users of HRT as percentage difference in hormonal measurements in relation to CYP19A1 polymorphisms

\begin{tabular}{|c|c|c|c|c|c|c|c|}
\hline \multirow[t]{2}{*}{ Genotype } & \multirow{2}{*}{$\begin{array}{l}n(\%) \\
n=339\end{array}$} & \multirow{2}{*}{$\begin{array}{l}\text { Estrone } \\
\Delta(95 \% \mathrm{Cl})^{\mathrm{a}}\end{array}$} & \multirow{2}{*}{$\begin{array}{l}P_{-} \\
\text {value }^{\mathrm{b}}\end{array}$} & Estrone sulphate & \multirow[t]{2}{*}{$P$-value } & SHBG & \multirow[t]{2}{*}{$P$-value } \\
\hline & & & & $\Delta(95 \% C l)^{a}$ & & $\Delta(95 \% C l)^{\mathrm{a}}$ & \\
\hline \multicolumn{8}{|l|}{ rs10519297 } \\
\hline AA & $81(24)$ & 0 (ref.) & & 0 (ref.) & & 0 (ref.) & \\
\hline$A G$ & $187(55)$ & $8(-4 ; 21)$ & 0.35 & $10(-1 ; 21)$ & 0.05 & $-5(-14 ; 6)$ & 0.66 \\
\hline GG & $71(21)$ & $1(-13 ; 16)$ & & $16(3 ; 31)$ & & $-2(-14 ; 11)$ & \\
\hline$A G+G G$ & $258(56)$ & $6(-6 ; 18)$ & 0.34 & $12(1 ; 23)$ & 0.03 & $-4(-13 ; 6)$ & 0.44 \\
\hline \multicolumn{8}{|l|}{ rs749292 } \\
\hline GG & $101(30)$ & 0 (ref.) & & 0 (ref.) & & 0 (ref.) & \\
\hline$A G$ & $169(50)$ & $-5(-15 ; 6)$ & 0.62 & $-11(-19 ;-2)$ & 0.007 & $-3(-12 ; 7)$ & 0.07 \\
\hline AA & $69(20)$ & $-5(-17 ; 9)$ & & $-16(-26 ;-6)$ & & $11(-2 ; 26)$ & \\
\hline$A G+A A$ & $238(70)$ & $-5(-14 ; 5)$ & 0.33 & $-12(-20 ;-4)$ & 0.004 & $1(-8 ; 11)$ & 0.82 \\
\hline \multicolumn{8}{|l|}{ rs1062033 } \\
\hline CC & $88(26)$ & 0 (ref.) & & 0 (ref.) & & 0 (ref.) & \\
\hline$C G$ & $180(53)$ & $-2(-13 ; 10)$ & 0.53 & $-10(-19 ;-1)$ & 0.01 & $-1(-11 ; 9)$ & 0.45 \\
\hline GG & $71(21)$ & $-7(-20 ; 6)$ & & $-16(-26 ;-6)$ & & $6(-7 ; 21)$ & \\
\hline$C G+G G$ & $251(74)$ & $-4(-14 ; 7)$ & 0.51 & $-12(-20 ;-3)$ & 0.007 & $1(-9 ; 11)$ & 0.88 \\
\hline \multicolumn{8}{|l|}{ rs10046 } \\
\hline AA & $93(27)$ & 0 (ref.) & & 0 (ref.) & & 0 (ref.) & \\
\hline$A G$ & $177(52)$ & $2(-9 ; 15)$ & 0.58 & $4(-5 ; 15)$ & 0.26 & $-1(-10 ; 10)$ & 0.94 \\
\hline GG & $69(20)$ & $-4(-17 ; 10)$ & & $11(-2 ; 25)$ & & $-2(-14 ; 11)$ & \\
\hline$A G+G G$ & $246(73)$ & $0(-10 ; 12)$ & 0.93 & $6(-3 ; 16)$ & 0.21 & $-1(-10 ; 9)$ & 0.82 \\
\hline \multicolumn{8}{|l|}{ rs4646 } \\
\hline CC & $186(55)$ & 0 (ref.) & & 0 (ref.) & & 0 (ref.) & \\
\hline CA & 133 (39) & $3(-7 ; 14)$ & 0.68 & $5(-3 ; 15)$ & 0.38 & $-4(-13 ; 5)$ & 0.59 \\
\hline AA & $20(6)$ & $-6(-23 ; 16)$ & & $10(-8 ; 31)$ & & $-5(-21 ; 15)$ & \\
\hline$C A+A A$ & $153(45)$ & $2(-8 ; 12)$ & 0.73 & $6(-3 ; 15)$ & 0.18 & $-4(-13 ; 4)$ & 0.30 \\
\hline \multicolumn{8}{|l|}{ rs6493487 } \\
\hline AA & $203(60)$ & 0 (ref.) & & 0 (ref.) & & 0 (ref.) & \\
\hline GA & $127(38)$ & $-5(-14 ; 5)$ & 0.27 & $4(-4 ; 14)$ & 0.63 & $-5(-13 ; 4)$ & 0.37 \\
\hline GG & $9(3)$ & $-19(-40 ; 9)$ & & $0(-23 ; 29)$ & & $-14(-34 ; 13)$ & \\
\hline $\mathrm{GA}+\mathrm{GG}$ & $136(41)$ & $-6(-15 ; 4)$ & 0.23 & $4(-4 ; 13)$ & 0.36 & $-5(-13 ; 3)$ & 0.22 \\
\hline \multicolumn{8}{|l|}{ rs2008691 } \\
\hline AA & $220(65)$ & 0 (ref.) & & 0 (ref.) & & 0 (ref.) & \\
\hline GA & 109 (32) & $4(-6 ; 15)$ & 0.35 & $3(-6 ; 12)$ & 0.83 & $2(-7 ; 12)$ & 0.17 \\
\hline GG & $10(3)$ & $21(-9 ; 60)$ & & $0(-21 ; 28)$ & & $27(-1 ; 64)$ & \\
\hline $\mathrm{GA}+\mathrm{GG}$ & 119 (35) & $5(-4 ; 16)$ & 0.29 & $2(-6 ; 12)$ & 0.57 & $4(-5 ; 14)$ & 0.37 \\
\hline \multicolumn{8}{|l|}{ rs3751591 } \\
\hline$\pi$ & $241(71)$ & 0 (ref.) & & 0 (ref.) & & 0 (ref.) & \\
\hline TC & $90(27)$ & $2(-9 ; 13)$ & 0.55 & $1(-8 ; 10)$ & 0.50 & $1(-9 ; 11)$ & 0.09 \\
\hline CC & $8(2)$ & $19(-13 ; 63)$ & & $18(-10 ; 54)$ & & $38(4 ; 83)$ & \\
\hline$C C$ vs. $T T+T C$ & $8(2)$ & $18(-14 ; 62)$ & 0.29 & $17(-10 ; 53)$ & 0.24 & $37(4 ; 82)$ & 0.03 \\
\hline
\end{tabular}


Table 2 Plasma levels of estrone, estrone sulphate and SHBG among 339 never and past users of HRT as percentage difference in hormonal measurements in relation to CYP19A1 polymorphisms (Continued)

\begin{tabular}{|c|c|c|c|c|c|c|c|}
\hline \multicolumn{8}{|c|}{ rs2445762 } \\
\hline$\pi$ & $175(52)$ & 0 (ref.) & & 0 (ref.) & & 0 (ref.) & \\
\hline TC & $142(42)$ & $-3(-12 ; 7)$ & 0.71 & $-1(-9 ; 8)$ & 0.71 & $-3(-19 ; 16)$ & 0.53 \\
\hline CC & $22(6)$ & $-7(-24 ; 13)$ & & $-7(-21 ; 10)$ & & $-5(-13 ; 4)$ & \\
\hline $\mathrm{TC}+\mathrm{CC}$ & $164(48)$ & $-3(-12 ; 6)$ & 0.47 & $-2(-10 ; 6)$ & 0.63 & $-5(-13 ; 4)$ & 0.27 \\
\hline \multicolumn{8}{|c|}{ rs11070844 } \\
\hline CC & 267 (79) & 0 (ref.) & & 0 (ref.) & & 0 (ref.) & \\
\hline TC & $68(20)$ & $17(4 ; 31)$ & 0.03 & $13(2 ; 25)$ & 0.04 & $6(-5 ; 18)$ & 0.20 \\
\hline$\pi$ & $4(1)$ & $16(-26 ; 79)$ & & $23(-16 ; 79)$ & & $36(-9 ; 103)$ & \\
\hline$T C+\pi$ & $72(21)$ & $17(4 ; 31)$ & 0.009 & $14(3 ; 25)$ & 0.01 & $7(-3 ; 19)$ & 0.18 \\
\hline
\end{tabular}

SHBG Sex-hormone binding globulin

$\triangle$ Percentage difference in hormonal measurements compared to WT

${ }^{a}$ Adjusted for age, smoking (never, past, current), alcohol intake (increment of $10 \mathrm{~g}$ per day) and BMl $\left(\mathrm{kg} / \mathrm{m}^{2}\right)$ at baseline

${ }^{\mathrm{b}} \mathrm{P}$-value for trend

$38 \%$ decreased risk of $\mathrm{BC}(\mathrm{IRR}=0.62$; $95 \% \mathrm{CI}$ : 0.361.08) (Additional file 8). When including alcohol in the model as $10 \mathrm{~g}$ alcohol per day, practically all CYP19A1 polymorphisms interacted with PPARG Pro $^{12} \mathrm{Ala}\left(P_{\text {int }}{ }^{-}\right.$ values between 0.03-0.10) (Additional file 9). Only $P P A R G$ Pro ${ }^{12}$ Ala wild type carriers were at significantly increased risk of BC. Neither PPARGC1A Gly ${ }^{482}$ Ser nor PPARGC1A $\mathrm{Thr}^{612}$ Met interacted with any of the CYP19A1 polymorphisms when inferring the $\mathrm{BC}$ risk per $10 \mathrm{~g}$ alcohol per day (Additional files 10 and 11). There were no interactions with NSAID use for combinations of CYP19A1 genotypes for $10 \mathrm{~g}$ alcohol per day (Additional file 12).

\section{RCT}

Baseline characteristics of the study participants are presented in Table 5, and mean hormone, ethanol and SHBG concentrations in Additional file 13. Baseline measurements (time $=0$ ) did not differ between the two intervention groups (results not shown). Intake of Ibuprofen and PPARG Pro ${ }^{12}$ Ala genotype were not associated with hormone or SHBG concentrations. However, there was a statistically significant effect of time on hormone concentrations (model B); that is, estrone, estrone sulphate and SHBG concentrations declined over the time period from 0 to $90 \mathrm{~min}\left(P_{\text {estrone }}=<0.0001, P_{\mathrm{SHBG}}=0.009\right.$ and $P_{\text {estrone sulphate }}=<0.0001$ ) (Figs. 4, 5 and 6), whereas the ethanol concentration increased as expected $\left(P_{\text {ethanol }}=\right.$ $<0.0001$ ) (Fig. 7). There was no effect of time in model A on any markers except for estrone concentrations, which increased at the latest time point $(1200 \mathrm{~min})$ compared to baseline $(\mathrm{t}=0)(P=0.02)$. BMI was significantly associated with concentrations of SHBG $(P=0.02)$ and ethanol $(P=0.04)$, such that women with high BMI also had higher blood concentrations.

\section{Discussion}

In the present study, polymorphisms in CYP19A1 were associated with circulating blood levels of female sexhormones and there was interaction between genotypes and alcohol consumption in relation to blood levels. Specifically, CYP19A1/rs1062033 was associated to both estrone sulphate levels and to alcohol-dependent differences in estrone sulphate levels. CYP19A1/rs3751591 was both associated with SHBG levels and with risk of $\mathrm{BC}$ such that homozygous variant allele carriers had increased levels of serum SHBG and were at increased risk of $\mathrm{BC}$. In addition we found indications of interaction between NSAID use, CYP19A1 polymorphisms and levels of circulating female sex-hormones. We found that CYP19A1 polymorphisms interacted with polymorphisms in PPARGC1A in relation to risk of $\mathrm{BC}$, but there was no interaction with alcohol intake. Additionally, we showed that acute alcohol consumption affected circulating blood hormone and SHBG levels, but Ibuprofen intake and PPARG Pro ${ }^{12} \mathrm{Ala}$ status did not affect the found sexhormone concentrations.

In the prospective study, we were able to show that inherent variations in CYP19A1 were associated with up to $24 \%$ differences in female sex-hormone levels, and CYP19A1/rs3751591 was both associated with SHBG levels and with risk of BC. CYP19A1/rs3751591 and the GGG/GAG (CYP19A1/A-rs10046-G, A-rs6493487-G, Ars10519297-G) haplotype combination were associated with $\mathrm{BC}$ risk, but these results were based on very low numbers of cases and should therefore be interpreted with caution. CYP19A1/rs3751591 has no known function; it was chosen as a tag SNP and is located in a recombination hot spot. However, our results are in agreement with several other studies showing association between CYP19A1 polymorphisms and estrogens $[53,55,56,66]$, but not BC risk [67-69]. The results 
Table 3 Plasma levels of estrone, estrone sulphate and SHBG among 325 never and past users of HRT, who were also current drinkers, as percentage difference in hormonal measurements per $10 \mathrm{~g} /$ day in alcohol intake

\begin{tabular}{|c|c|c|c|c|c|c|c|}
\hline \multirow[t]{2}{*}{ Genotype } & $n(\%)$ & Estrone & \multirow[t]{2}{*}{$P$-value ${ }^{b}$} & Estrone sulphate & \multirow[t]{2}{*}{$P$-value ${ }^{b}$} & SHBG & \multirow[t]{2}{*}{$P$-value ${ }^{b}$} \\
\hline & $n=325$ & $\Delta(95 \% C l)^{a}$ & & $\Delta(95 \% C l)^{\mathrm{a}}$ & & $\Delta(95 \% \mathrm{Cl})^{\mathrm{a}}$ & \\
\hline \multicolumn{8}{|l|}{ rs10519297 } \\
\hline AA & $74(23)$ & $2(-4 ; 9)$ & & $3(-3 ; 9)$ & & $-5(-11 ; 0)$ & \\
\hline$A G$ & $182(56)$ & $3(-1 ; 6)$ & 0.82 & $3(0 ; 7)$ & 0.17 & $-6(-9 ;-3)$ & 0.23 \\
\hline GG & $69(21)$ & $1(-5 ; 6)$ & & $4(0 ; 9)$ & & $-3(-7 ; 2)$ & \\
\hline$A G+G G$ & $251(77)$ & $2(-1 ; 5)$ & 0.54 & $4(1 ; 6)$ & 0.08 & $-5(-8 ;-2)$ & 0.27 \\
\hline \multicolumn{8}{|l|}{ rs749292 } \\
\hline GG & $98(30)$ & $3(-2 ; 7)$ & & $4(1 ; 8)$ & & $-5(-8 ;-1)$ & \\
\hline$A G$ & $165(51)$ & $1(-3 ; 6)$ & 0.96 & $3(0 ; 7)$ & 0.38 & $-6(-9 ;-2)$ & 0.94 \\
\hline $\mathrm{AA}$ & $62(19)$ & $2(-5 ; 10)$ & & $-1(-7 ; 6)$ & & $0(-7 ; 6)$ & \\
\hline$A G+A A$ & $227(70)$ & $1(-2 ; 5)$ & 0.85 & $3(-1 ; 6)$ & 0.15 & $-5(-8 ;-1)$ & 0.95 \\
\hline \multicolumn{8}{|l|}{ rs1062033 } \\
\hline CC & $86(26)$ & $1(-3 ; 6)$ & & $4(0 ; 8)$ & & $-5(-9 ;-1)$ & \\
\hline CG & $175(54)$ & $3(-1 ; 7)$ & 0.76 & $4(0 ; 7)$ & 0.11 & $-5(-8 ;-2)$ & 0.67 \\
\hline GG & $64(20)$ & $1(-6 ; 8)$ & & $1(-4 ; 7)$ & & $-4(-9 ; 2)$ & \\
\hline$C G+G G$ & $239(74)$ & $2(-1 ; 6)$ & 0.45 & $3(0 ; 7)$ & 0.03 & $-5(-8 ;-2)$ & 0.90 \\
\hline \multicolumn{8}{|l|}{ rs10046 } \\
\hline $\mathrm{AA}$ & $85(26)$ & $3(-3 ; 10)$ & & $4(-2 ; 10)$ & & $-7(-12 ;-1)$ & \\
\hline$A G$ & $173(53)$ & $2(-1 ; 7)$ & 0.89 & $3(0 ; 7)$ & 0.29 & $-6(-9 ;-3)$ & 0.06 \\
\hline GG & $67(21)$ & $1(-4 ; 5)$ & & $3(0 ; 8)$ & & $-3(-7 ; 1)$ & \\
\hline$A G+G G$ & $240(74)$ & $2(-1 ; 5)$ & 0.64 & $3(1 ; 6)$ & 0.22 & $-5(-7 ;-2)$ & 0.24 \\
\hline \multicolumn{8}{|l|}{ rs4646 } \\
\hline CC & $177(54)$ & $3(-2 ; 7)$ & & $4(0 ; 7)$ & & $-4(-8 ;-1)$ & \\
\hline CA & $129(40)$ & $2(-2 ; 6)$ & 0.49 & $3(0 ; 7)$ & 0.30 & $-5(-8 ;-2)$ & 0.87 \\
\hline AA & $19(6)$ & $-6(-18 ; 7)$ & & $6(-5 ; 19)$ & & $-8(-18 ; 4)$ & \\
\hline$C A+A A$ & $148(46)$ & $1(-2 ; 5)$ & 0.41 & $3(0 ; 7)$ & 0.14 & $-5(-8 ;-2)$ & 0.59 \\
\hline \multicolumn{8}{|l|}{ rs6493487 } \\
\hline AA & $192(59)$ & $3(-1 ; 8)$ & & $3(-1 ; 7)$ & & $-5(-9 ;-1)$ & \\
\hline GA & $125(39)$ & $2(-2 ; 5)$ & 0.79 & $4(1 ; 8)$ & 0.64 & $-5(-8 ;-2)$ & 0.60 \\
\hline GG & $8(2)$ & $-1(-11 ; 11)$ & & $-1(-10 ; 9)$ & & $-5(-14 ; 5)$ & \\
\hline$G A+G G$ & $133(41)$ & $1(-2 ; 5)$ & 0.79 & $4(1 ; 7)$ & 0.97 & $-5(-8 ;-2)$ & 0.33 \\
\hline \multicolumn{8}{|l|}{ rs2008691 } \\
\hline \multirow[t]{2}{*}{ AA } & 210 & $2(-2 ; 6)$ & & $5(2 ; 8)$ & & $-6(-9 ;-3)$ & \\
\hline & (65) & & & & & & \\
\hline GA & $106(32)$ & $2(-2 ; 6)$ & 0.67 & $1(-2 ; 5)$ & 0.03 & $-4(-8 ; 0)$ & 0.41 \\
\hline GG & $9(3)$ & $12(-4 ; 31)$ & & $10(-3 ; 26)$ & & $6(-7 ; 22)$ & \\
\hline$G A+G G$ & $115(35)$ & $2(-2 ; 7)$ & 0.70 & $2(-2 ; 6)$ & 0.02 & $-4(-7 ; 0)$ & 0.31 \\
\hline \multicolumn{8}{|l|}{ rs3751591 } \\
\hline$\pi$ & $232(72)$ & $2(-1 ; 6)$ & & $4(1 ; 7)$ & & $-5(-8 ;-2)$ & \\
\hline TC & $85(26)$ & $1(-3 ; 6)$ & 0.78 & $2(-2 ; 6)$ & 0.70 & $-5(-8 ;-1)$ & 0.90 \\
\hline CC & $8(2)$ & $11(-7 ; 31)$ & & $9(-6 ; 26)$ & & $10(-6 ; 28)$ & \\
\hline CC vs. TT $+\mathrm{TC}$ & $8(2)$ & $11(-7 ; 31)$ & 0.81 & $9(-6 ; 26)$ & 0.74 & $10(-6 ; 28)$ & 0.86 \\
\hline
\end{tabular}


Table 3 Plasma levels of estrone, estrone sulphate and SHBG among 325 never and past users of HRT, who were also current drinkers, as percentage difference in hormonal measurements per $10 \mathrm{~g} /$ day in alcohol intake (Continued)

\begin{tabular}{|c|c|c|c|c|c|c|c|}
\hline \multicolumn{8}{|c|}{ rs2445762 } \\
\hline$\pi$ & $166(51)$ & $2(-1 ; 6)$ & & $3(0 ; 6)$ & & $-4(-7 ;-1)$ & \\
\hline TC & $139(43)$ & $1(-3 ; 6)$ & 0.94 & $5(1 ; 9)$ & 0.19 & $-6(-10 ;-2)$ & 0.72 \\
\hline CC & $20(6)$ & $3(-9 ; 16)$ & & $-2(-11 ; 8)$ & & $-8(-17 ; 2)$ & \\
\hline $\mathrm{TC}+\mathrm{CC}$ & 159 (49) & $1(-3 ; 6)$ & 1.00 & $4(0 ; 8)$ & 0.17 & $-6(-10 ;-3)$ & 0.61 \\
\hline \multicolumn{8}{|c|}{ rs11070844 } \\
\hline$C C$ & $255(78)$ & $1(-2 ; 5)$ & & $3(0 ; 6)$ & & $-4(-7 ;-1)$ & \\
\hline TC & $66(21)$ & $5(-1 ; 11)$ & 0.73 & $7(1 ; 12)$ & 0.92 & $-7(-12 ;-3)$ & 0.06 \\
\hline$\pi$ & $4(1)$ & $4(-20 ; 37)$ & & $15(-9 ; 45)$ & & $11(-13 ; 42)$ & \\
\hline$T C+\pi$ & $70(22)$ & $5(-1 ; 11)$ & 0.42 & $7(2 ; 12)$ & 0.74 & $-7(-12 ;-2)$ & 0.03 \\
\hline
\end{tabular}

SHBG Sex-hormone binding globulin

$\triangle$ Percentage difference in hormonal measurements per $10 \mathrm{~g} /$ day difference in alcohol intake

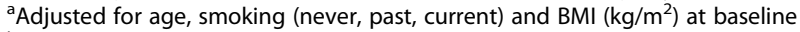

${ }^{b}$ P-value for interaction. All interactions were kept in the models in all analyses even though there was no interaction

may indicate that the $10-20 \%$ genetically determined variation in sex hormone levels contributes little to $\mathrm{BC}$ risk and thus, that other factors may contribute more to hormone-dependent BC risk. These factors could be hormone replacement therapy, child birth, and age of menarche and menopause.

We found no evidence of interaction between genetically determined variation in aromatase and PPAR $\gamma$ activity. When interaction with alcohol was included in the analysis, we found that only the PPARG Pro $^{12}$ Ala wild type carriers were at significantly increased risk of $B C$ irrespectively of CYP19A1 genotypes. This indicates that the effect of the PPARG Pro ${ }^{12}$ Ala polymorphism is very strong and that the CYP19A1 polymorphisms only have minor influence on $\mathrm{BC}$ risk. We observed a possibly interaction between aromatase and PGC- $1 \alpha$, however, none of the PPARGC1A polymorphisms interacted with both CYP19A1 polymorphisms and alcohol. Almost all risk estimates were above unity indicating a strong effect of alcohol regardless of genotype combinations. We have previously found evidence of PPARG and PPARGC1A being involved in alcohol-related $B C$ [30]; however, based on the present findings, we cannot extend this mechanism to include aromatase. This may indicate that PPAR $\gamma$ mediates alcohol-related $\mathrm{BC}$ by additional mechanisms in addition to the one involving effects on aromatase.

We used a nested case-control design for the prospective study, which together with complete follow-up minimizes selection bias. In addition, information on life style factors was collected at enrolment, which minimizes the risk for differential misclassification between cases and controls. The study is fairly large to study main effects, it is homogenous and alcohol consumption is relatively high in the $\mathrm{DCH}$ cohort [70] making it suitable for studying gene-environment interactions with alcohol. However, we are aware that there are several limitations in studying gene-environment interaction with NSAID use including the limited power. The information on NSAID use retrieved from the FFQ may not necessarily reflect a long-term chronic use which is considered necessary to confer an effect on carcinogenesis [71, 72]. Moreover, NSAID use included different types of pain killers such as paracetamol, aspirin and Ibuprofen, which have different pharmacological effects and also different effect in relation to BC risk [42]. The genes were carefully selected based on their role in steroidogenesis and alcohol-related BC. The CYP19A1 polymorphisms were mainly tag SNPs, whereas the PPARG and PPARGC1A polymorphisms were functional. However, only the interaction between CYP19A1/rs4646 and PPARGC1A Thr ${ }^{612}$ Met, and the effect of CYP19A1/rs749292 on estrone sulphate levels withstood correction for multiple analyses when taking the number of analysed SNPs into account (main effects). Therefore, some of the results based on the prospective study may be due to chance.

After acute ingestion of alcohol, estrone, estrone sulphate and SHBG levels declined significantly and correlated inversely with ethanol blood levels. Both controlled acute trials [16, 20-23, 73], controlled trials with fixed amounts of alcohol over longer periods $[17,18]$ and observational studies $[12-15,24,25]$ have reported increased levels of estrogens after consumption of alcohol. Most acute studies have only measured estradiol levels, which have been consistently increased after consumption of alcohol [16, 19-23], whereas estrone has only been measured in two acute studies in women using oral contraceptives [23] and HRT [20], respectively. In the study by Sarkola et al., estradiol increased after acute alcohol administration, but alcohol intake had no effect on estrone levels. However, the estradiol-to-estrone ratio was significantly increased. In a study by Ginsburg et al., estrone declined after acute alcohol consumption, 
Table 4 IRR for BC in relation to the studied polymorphisms among postmenopausal women in the DCH cohort

\begin{tabular}{|c|c|c|c|c|c|}
\hline & $\begin{array}{l}n_{\text {cases }}(\%) \\
(n=687)\end{array}$ & $\begin{array}{l}n_{\text {control }}(\%) \\
(n=687)\end{array}$ & $\operatorname{IRR}^{\mathrm{a}}(95 \% \mathrm{Cl})$ & $\operatorname{IRR}^{\mathrm{b}}(95 \% \mathrm{Cl})$ & $P$-value \\
\hline \multicolumn{6}{|l|}{ rs10519297 } \\
\hline AA & $170(25)$ & $174(25)$ & 1.00 (ref.) & 1.00 (ref.) & \\
\hline$A G$ & $341(50)$ & $361(53)$ & $0.98(0.76-1.27)$ & $0.94(0.72-1.23)$ & 0.15 \\
\hline GG & $176(25)$ & $152(22)$ & $1.23(0.90-1.68)$ & $1.25(0.91-1.72)$ & \\
\hline$A G+G G$ & $511(75)$ & $513(54)$ & $1.05(0.82-1.34)$ & $1.03(0.80-1.32)$ & 0.83 \\
\hline \multicolumn{6}{|l|}{ rs749292 } \\
\hline GG & $216(31)$ & $203(30)$ & 1.00 (ref.) & 1.00 (ref.) & \\
\hline$A G$ & $332(48)$ & $352(51)$ & $0.89(0.69-1.14)$ & $0.89(0.69-1.16)$ & 0.62 \\
\hline AA & $139(20)$ & $132(19)$ & $0.97(0.71-1.33)$ & $0.99(0.72-1.37)$ & \\
\hline$A G+A A$ & $471(68)$ & $484(70)$ & $0.91(0.72-1.15)$ & $0.92(0.72-1.17)$ & 0.50 \\
\hline \multicolumn{6}{|l|}{ rs1062033 } \\
\hline CC & $203(30)$ & $186(27)$ & 1.00 (ref.) & 1.00 (ref.) & \\
\hline$C G$ & $333(48)$ & $354(52)$ & $0.85(0.66-1.10)$ & $0.85(0.65-1.11)$ & 0.46 \\
\hline GG & $151(22)$ & $147(21)$ & $0.92(0.67-1.25)$ & $0.94(0.68-1.28)$ & \\
\hline$C G+G G$ & $484(70)$ & $501(73)$ & $0.87(0.68-1.11)$ & $0.88(0.68-1.12)$ & 0.30 \\
\hline \multicolumn{6}{|l|}{ rs10046 } \\
\hline AA & $182(27)$ & $188(28)$ & 1.00 (ref.) & 1.00 (ref.) & \\
\hline$A G$ & $346(50)$ & $353(51)$ & $1.02(0.79-1.31)$ & $0.97(0.75-1.26)$ & 0.52 \\
\hline GG & $159(23)$ & $146(21)$ & $1.16(0.85-1.57)$ & $1.15(0.84-1.57)$ & \\
\hline$A G+G G$ & $505(73)$ & $499(72)$ & $1.06(0.84-1.34)$ & $1.02(0.80-1.31)$ & 0.86 \\
\hline \multicolumn{6}{|l|}{ rs 4646} \\
\hline CC & $372(54)$ & $371(54)$ & 1.00 (ref.) & 1.00 (ref.) & \\
\hline$C A$ & $265(39)$ & $262(38)$ & $1.00(0.80-1.25)$ & $0.97(0.77-1.21)$ & 0.95 \\
\hline AA & $50(7)$ & $54(8)$ & $0.96(0.63-1.45)$ & $1.00(0.65-1.53)$ & \\
\hline$C A+A A$ & $315(46)$ & $316(46)$ & $0.99(0.81-1.22)$ & $0.97(0.78-1.20)$ & 0.78 \\
\hline \multicolumn{6}{|l|}{ rs6493487 } \\
\hline AA & 407 (59) & $430(62)$ & 1.00 (ref.) & 1.00 (ref.) & \\
\hline GA & $245(36)$ & $218(32)$ & $1.23(0.98-1.55)$ & $1.24(0.98-1.58)$ & 0.16 \\
\hline GG & $35(5)$ & $39(6)$ & $0.96(0.60-1.54)$ & $0.88(0.54-1.44)$ & \\
\hline$G A+G G$ & $280(40)$ & $257(38)$ & $1.19(0.95-1.48)$ & $1.18(0.94-1.48)$ & 0.16 \\
\hline \multicolumn{6}{|l|}{ rs2008691 } \\
\hline AA & $479(70)$ & $470(68)$ & 1.00 (ref.) & 1.00 (ref.) & \\
\hline GA & $179(26)$ & $198(29)$ & $0.88(0.69-1.11)$ & $0.88(0.69-1.12)$ & 0.25 \\
\hline GG & $29(4)$ & $19(3)$ & $1.43(0.80-2.57)$ & $1.45(0.80-2.64)$ & \\
\hline $\mathrm{GA}+\mathrm{GG}$ & $208(30)$ & $217(32)$ & $0.93(0.74-1.17)$ & $0.93(0.74-1.18)$ & 0.57 \\
\hline \multicolumn{6}{|l|}{ rs3751591 } \\
\hline$\pi$ & $479(70)$ & $498(72)$ & 1.00 (ref.) & 1.00 (ref.) & \\
\hline TC & $182(26)$ & $176(26)$ & $1.07(0.84-1.36)$ & $1.07(0.83-1.37)$ & 0.60 \\
\hline CC & $26(4)$ & $13(2)$ & $2.13(1.04-4.39)$ & $2.12(1.02-4.43)$ & 0.04 \\
\hline $\mathrm{TC}+\mathrm{CC}$ & $208(30)$ & $189(28)$ & $1.13(0.89-1.42)$ & $1.13(0.89-1.44)$ & 0.31 \\
\hline$C C$ vs. $T+T^{d}$ & $26(4)$ & $13(2)$ & $2.09(1.02-4.29)$ & $2.09(1.00-4.34)$ & 0.05 \\
\hline
\end{tabular}


Table 4 IRR for BC in relation to the studied polymorphisms among postmenopausal women in the DCH cohort (Continued)

\begin{tabular}{|c|c|c|c|c|c|}
\hline \multicolumn{6}{|c|}{ rs2445762 } \\
\hline$\pi$ & $359(52)$ & $365(53)$ & 1.00 (ref.) & 1.00 (ref.) & \\
\hline TC & $278(40)$ & $276(40)$ & $1.02(0.81-1.27)$ & $1.04(0.83-1.31)$ & \multirow[t]{2}{*}{0.74} \\
\hline CC & $50(8)$ & $46(7)$ & $1.10(0.72-1.69)$ & $1.19(0.76-1.85)$ & \\
\hline $\mathrm{TC}+\mathrm{CC}$ & $328(48)$ & $322(47)$ & $1.03(0.83-1.27)$ & $1.06(0.85-1.32)$ & 0.61 \\
\hline \multicolumn{6}{|c|}{ rs11070844 } \\
\hline CC & $552(80)$ & $556(81)$ & 1.00 (ref.) & 1.00 (ref.) & \\
\hline TC & $129(19)$ & $125(18)$ & $1.06(0.801-1.39)$ & $1.06(0.80-1.40)$ & \multirow[t]{2}{*}{0.88} \\
\hline$\pi$ & $6(1)$ & $6(1)$ & $1.01(0.33-3.13)$ & $0.86(0.27-2.73)$ & \\
\hline $\mathrm{TC}+\mathrm{TT}$ & $135(20)$ & $131(19)$ & $1.06(0.81-1.38)$ & $1.05(0.80-1.38)$ & 0.73 \\
\hline
\end{tabular}

whereas estradiol increased. Long-term interventional and observational studies most consistently report either increased levels of estradiol $[13,15,18,25,74-76]$ and/or estrone $[12,13,18,75,76]$ and/or estrone sulphate $[14,17,75]$ and decreased SHBG levels [12, 75-77] among alcohol drinkers in both pre- and postmenopausal women. However, estradiol and estrone have very short half-lives of $35 \mathrm{~min}$, whereas estrone sulphate has a half-life of 5-7 h [17]. Therefore, only acute studies, where blood is collected immediately after alcohol ingestion, are able to correctly measure the effect of alcohol on estradiol and estrone blood levels. On the other hand, acute ingestion of alcohol may have different effects on sex-steroids than chronic alcohol consumption, as illustrated by studies on alcohol consumption and immune effects [78]. It has been suggested that acute ingestion of alcohol affects catabolism of the hormones in the liver rather than synthesis [22, 23, $79,80]$. In the liver, alcohol consumption increases the [NADH]: $[\mathrm{NAD}+]$ ratio which leads to a decreased catabolism of sex-hormones mediated by $17 \beta$-hydroxysteroid dehydrogenase type 2 enzyme resulting in increased levels of testosterone and estradiol and decreased levels of androstenedione and estrone. Furthermore, it has been shown that only long-term chronic ingestion of alcohol induces

Table 5 Baseline characteristics of the RTC study participants

\begin{tabular}{|c|c|c|c|c|c|}
\hline \multirow[t]{2}{*}{ Characteristic } & \multicolumn{2}{|c|}{ PPARY2 $\operatorname{Pro}^{12}(n=18)$} & \multicolumn{2}{|c|}{ PPARY2 ${ }^{12}$ Ala $(n=7)$} & \multirow[t]{2}{*}{$P$-values ${ }^{d}$} \\
\hline & Median & Range & Median & Range & \\
\hline $\mathrm{Age}^{\mathrm{a}}$, years & 58.5 & $(49-70)$ & 55 & $(47-67)$ & 0.28 \\
\hline Weight, kg & 64.1 & $(50.1-86.5)$ & 59.8 & $(57.2-68.4)$ & 0.27 \\
\hline $\mathrm{BMI}, \mathrm{kg} / \mathrm{m}^{2}$ & 23.5 & $(19.1-26.9)$ & 22.4 & $(19.4-24.5)$ & 0.14 \\
\hline Years since last menses & 5.5 & $(1-25)$ & 6 & $(3-16)$ & 0.46 \\
\hline Alcohol intake/week & 6.5 & $(1-15)$ & 6 & $(3.5-14)$ & 0.70 \\
\hline \multirow[t]{2}{*}{ Characteristic } & \multicolumn{2}{|c|}{ PPARY2 Pro ${ }^{12}(n=18)$} & \multicolumn{2}{|c|}{ PPARY2 ${ }^{12}$ Ala $(n=7)$} & \\
\hline & No. & $\%$ & No. & $\%$ & \\
\hline \multicolumn{6}{|l|}{ Menopause type } \\
\hline Natural $^{\mathrm{b}}$ & 17 & 94.4 & 6 & 85.7 & \\
\hline Hysterectomy $^{c}$ & 1 & 6.6 & 1 & 14.3 & \\
\hline \multicolumn{6}{|l|}{ Smoking status } \\
\hline Never & 10 & 55.6 & 5 & 71.4 & \\
\hline Former & 8 & 44.4 & 2 & 28.6 & \\
\hline
\end{tabular}

Characteristics of participants from the RCT divided by genotype

${ }^{a}$ One participant was only 48 years, but had not had her menses for 6 years. All other participants were older than 50 years

${ }^{\mathrm{b}}$ One participant had had a unilateral oophorectomy

'One participant had a combined hysterectomy and oophorectomy; and one participant had a hysterectomy before last menses, but was older than 60 years

${ }^{d} P$-values for comparison of baseline characteristics using Student's t-test 


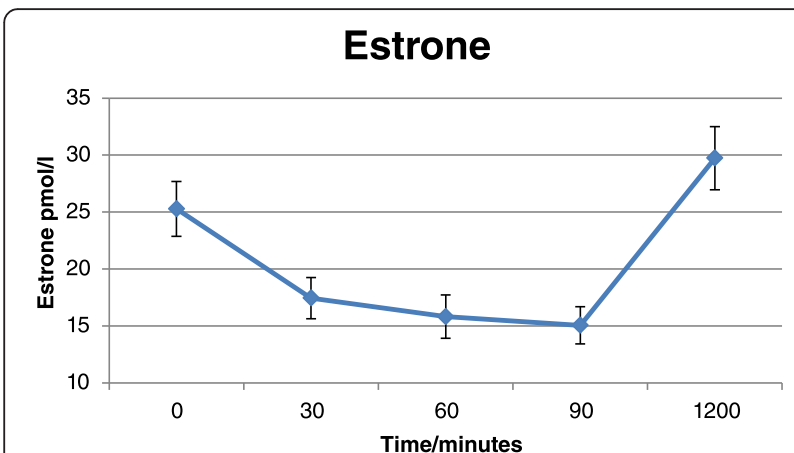

Fig. 4 Estrone concentrations as a function of time. Zero values have been replaced by half of the Limit of Detection $=0.5 \mathrm{pmol} / \mathrm{L}$. Values represent pooled mean measurements \pm SEM $(n=50)$. $P_{\text {time }}$ $(0-90 \mathrm{~min})=<0.0001 ; P_{\text {time }}(0-1200 \mathrm{~min})=0.02$

aromatase [22, 34]. We detected a decline in estrone sulphate levels shortly after ingestion of alcohol, supporting that acute alcohol intake affects metabolism of female sexhormone, which may explain the discrepancies between results from observational and experimental studies.

The RCT also has several limitations. Our aim was to conduct a pilot study to examine whether the PPARG Pro ${ }^{12}$ Ala polymorphisms had any influence on the blood hormone level after consumption of alcohol with and without concurrent intake of Ibuprofen. Based on a controlled long-term feeding study [17], we should have an $80 \%$ chance of detecting a change in hormone levels of $10 \%$ on a $5 \%$ significance level $(\alpha=0.05)$ with 11 participants in each group. However, we were only able to recruit 7 PPARG ${ }^{12}$ Ala variant-carriers. Nevertheless, we found statistically significant decreases in estrone, estrone sulphate and SHBG levels. We did not include an alcohol placebo group because our main aim was to examine the effect of concurrent use of Ibuprofen and alcohol consumption on circulating hormone levels. Therefore, the hormone effect could potentially be an effect of the ingredients in the alcoholic drink. However, other interventional studies have used similar ingredients in the alcoholic test drink e.g. different types of fruit juices $[17,18,20,22,23,73,81]$ or pure

\section{SHBG}

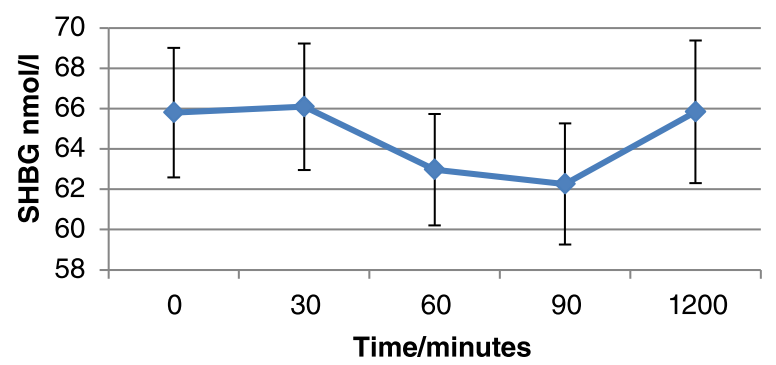

Fig. 5 SHBG concentrations as a function of time. Values represent pooled mean measurements $\pm \operatorname{SEM}(n=50)$. $P_{\text {time }}(0-90 \mathrm{~min})=0.009$

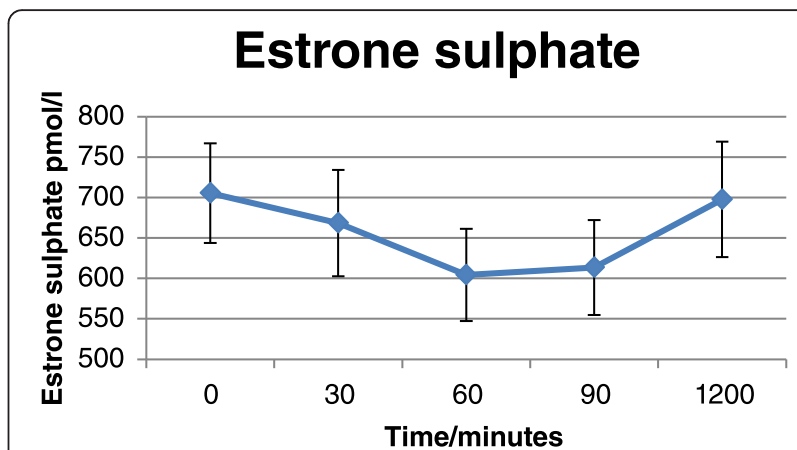

Fig. 6 Estrone sulphate concentrations as a function of time. Values represent pooled mean measurements \pm SEM $(n=50)$.

$P_{\text {time }}(0-90 \mathrm{~min})=<0.0001$

glucose [16] without an effect on hormone levels. In order to verify the results from the present study, a new study should preferably include a placebo group, and if feasible for ethical reasons should also assess effects over a longer exposure period. Moreover, other steroid hormones should be included to examine other effects of alcohol consumption on steroidogenesis and metabolism. The method used to measure hormones differs from all the other studies mentioned in this paper. We determined the hormones by LC-MS because of its documented specificity [82] and to avoid overestimation due to lack of specificity of antibodies, which is a well-known challenge with conventional radioimmunoassays [82, 83]. However, MS methods suffer from lack of sensitivity and, consequently, we were not able to include results on estradiol measurements and $11 \%$ of the estrone measurements had levels below zero which further decreased the statistical power.

\section{Conclusion}

Our results show that alcohol consumption and inherent variations in CYP19A1 influence the level of circulating blood sex-hormones. Specifically, CYP19A1/rs1062033 was associated to both estrone sulphate levels and to alcohol-dependent differences in estrone sulphate levels. CYP19A1/rs3751591 was both associated with SHBG

\section{Ethanol}

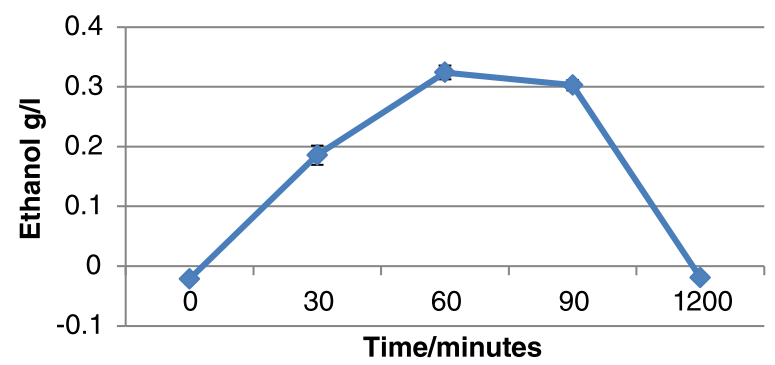

Fig. 7 Ethanol concentrations as a function of time. Values represent pooled mean measurements $\pm \operatorname{SEM}(n=50)$. $P_{\text {time }}(0-90 \mathrm{~min})=<0.0001$ 
levels and with risk of $\mathrm{BC}$ such that homozygous variant allele carriers had increased levels of serum SHBG and were at increased risk of $\mathrm{BC}$. However, the genetically determined differences in sex hormone levels were not convincingly associated with $\mathrm{BC}$ risk. The results therefore indicate that the genetically determined variation in sex-hormone levels contributes little to BC risk and thus, that other factors may contribute more to hormonedependent $\mathrm{BC}$ risk. In addition, our results indicate that acute and chronic alcohol consumption may affect metabolism and biosynthesis of estrogens differently. We were unable to show that aromatase is part of the mechanism of PPAR $\gamma$-dependent alcohol-related BC.

\section{Additional files}

Additional file 1: LD plot of CYP19A1 with illustration of rs3751591 (in green square) located between two large haplotype blocks (genotyping data set from Utah residents with ancestry from Northern and Western Europe (CEU, version 3, release 2) in combination with Haploview (version 4.2, Broad Institute, Cambridge USA). (DOCX $487 \mathrm{~kb}$ )

Additional file 2: Plasma levels of estrone, estrone sulphate and SHBG among 335 never and past users of hormone replacement therapy as percentage difference in hormonal measurements in relation to CYP19A1 polymorphisms divided by usage of NSAID. (DOCX $25 \mathrm{~kb}$ )

Additional file 3: Risk estimates for different combinations of CYP19A1 haplotypes in relation to risk of BC. (DOCX $12 \mathrm{~kb}$ )

Additional file 4 IRR for BC in relation to CYP19A1 polymorphisms per increment of $10 \mathrm{~g}$ alcohol per day. (DOCX $22 \mathrm{~kb}$ )

Additional file 5: IRR for BC in relation to use of NSAID and CYP19A1 polymorphisms. (DOCX $30 \mathrm{~kb}$ )

Additional file 6: IRR for $B C$ in relation to combinations of PPARG Pro12Ala and CYP19A1 genotypes. (DOCX $33 \mathrm{~kb}$ )

Additional file 7: IRR for $B C$ in relation to combinations of PPARGC1A Gly482Ser and CYP19A1 genotypes. (DOCX $30 \mathrm{~kb}$ )

Additional file 8: IRR for $B C$ in relation to combinations of PPARGC1A Thr612Met and CYP19A1 genotypes. (DOCX $28 \mathrm{~kb}$ )

Additional file 9: IRR for $B C$ per $10 \mathrm{~g}$ alcohol/day for combinations of PPARG Pro12Ala and CYP19A1 genotypes. (DOCX $30 \mathrm{~kb}$ )

Additional file 10: IRR for $B C$ per $10 \mathrm{~g}$ alcohol/day for combinations PPARGC1A Gly482Ser and CYP19A1 genotypes. (DOCX $29 \mathrm{~kb}$ )

Additional file 11: IRR for $B C$ per $10 \mathrm{~g}$ alcohol/day for combinations of PPARGC1A Thr612Met and CYP19A1 genotypes. (DOCX $28 \mathrm{~kb}$ )

Additional file 12: IRR for $B C$ per $10 \mathrm{~g}$ alcohol/day in relation to combinations of NSAID use and CYP19A1 polymorphisms. (DOCX $29 \mathrm{~kb})$

Additional file 13: Hormones, SHBG and ethanol measurements after acute ingestion of alcohol from the RCT study. (DOCX $19 \mathrm{~kb}$ )

\footnotetext{
Abbreviations

BC: Breast cancer; BMI: Body Mass Index; Cl: Confidence interval; CV: Coefficient of variation; CYP19A1: Cytochrome P450, family 19, subfamily A, polypeptide 1: encodes aromatase; DCH: Diet, Cancer and Health; HRT: Hormone replacement therapy; IRR: Incidence rate ratios; LC-MS: LiquidChromatography Mass-Spectrometry; LOD: Limit of detection; NSAID: Nonsteroidal anti-inflammatory drugs; PGC-1a: Peroxisome proliferator-activated receptor gamma coactivator 1-a, encoded by PPARGC1A; PPARY: Peroxisome proliferator-activated receptor gamma, encoded by PPARG; RCT: Randomised controlled trial; RXR: Retinoid X receptor; SNP: Single nucleotide polymorphism.
}

\section{Competing interests}

The authors declare that they have no competing interests.

\section{Authors' contributions}

TIK participated in the design of both studies, managed the RCT, carried out extraction of DNA and genotyping of the RCT, performed statistical analyses of the case-control study and drafted the manuscript. DMJ participated in the design and statistical analyses of the case-control study, and carried out genotyping of four of the CYP19A1 polymorphisms. GRH participated in the design and coordination of the RCT, carried out analyses of ethanol and helped to draft the manuscript. AC and DMH carried out the analyses of the estrogens and SHBG and advised concerning these assays. HMS performed the statistical analyses of the RCT. LOD was responsible for the RCT and participated in the design of the study. AT designed the case-control study and contributed with reagents, materials and analysis tools. UV conceived of both studies, and participated in their design and helped to draft the manuscript. All authors read and approved the final manuscript.

\section{Acknowledgements}

We thank Lene Svensson, Annette Landin, Ümmühan Celik, Susan Svane Laursen, Nick Martinussen and Katja Boll for excellent technical support; and Jane Christensen for statistical consulting on the DCH cohort study data.

\section{Author details}

${ }^{1}$ Technical University of Denmark, National Food Institute, Søborg, Denmark. ${ }^{2}$ Danish Cancer Society Research Center, Copenhagen, Denmark. ${ }^{3}$ Research Centre for Prevention and Health, Rigshospitalet - Glostrup, Glostrup, Denmark. ${ }^{4}$ Section of Environmental Health, University of Copenhagen, Copenhagen, Denmark. ${ }^{5}$ Department of Clinical Biochemistry and Immunology, Statens Serum Institute, Copenhagen, Denmark. 'Department of Nutrition, Exercise and Sports, University of Copenhagen, Copenhagen, Denmark. ${ }^{7}$ National Research Centre for the Working Environment, Copenhagen, Denmark.

Received: 8 June 2015 Accepted: 14 April 2016

Published online: 21 April 2016

\section{References}

1. Singletary KW, Gapstur SM. Alcohol and breast cancer: review of epidemiologic and experimental evidence and potential mechanisms. JAMA. 2001;286(17):2143-51.

2. Boffetta P, Hashibe M. Alcohol and cancer. Lancet Oncol. 2006;7(2):149-56.

3. Pelucchi C, Tramacere I, Boffetta P, Negri E, La VC. Alcohol consumption and cancer risk. Nutr Cancer. 2011:63(7):983-90.

4. Dumitrescu RG, Shields PG. The etiology of alcohol-induced breast cancer. Alcohol. 2005;35(3):213-25.

5. Tjonneland A, Thomsen BL, Stripp C, Christensen J, Overvad K, Mellemkaer L, Gronbaek M, Olsen JH. Alcohol intake, drinking patterns and risk of postmenopausal breast cancer in Denmark: a prospective cohort study. Cancer Causes Control. 2003;14(3):277-84.

6. Hamajima N, Hirose K, Tajima K, Rohan T, Calle EE, Heath Jr CW, et al. Alcohol, tobacco and breast cancer-collaborative reanalysis of individual data from 53 epidemiological studies, including 58,515 women with breast cancer and 95,067 women without the disease. Br J Cancer. 2002;87(11): $1234-45$.

7. Smith-Warner SA, Spiegelman D, Yaun SS, van den Brandt PA, Folsom AR, Goldbohm RA, Graham S, Holmberg L, Howe GR, Marshall JR, Miller AB, Potter JD, Speizer FE, Willett WC, Wolk A, Hunter DJ. Alcohol and breast cancer in women: a pooled analysis of cohort studies. JAMA. 1998;279(7):535-40.

8. Benzon LS, Vogel U, Christensen J, Hansen RD, Wallin H, Overvad K, Tjonneland A, Tolstrup J. Interaction between ADH1C Arg(272)Gln and alcohol intake in relation to breast cancer risk suggests that ethanol is the causal factor in alcohol related breast cancer. Cancer Lett. 2010;295(2):191-7.

9. Tjonneland A. Lifestyle Risk Factors for Breast Cancer - Diet, Cancer and Health, a Prospective Cohort Study in Denmark. Copenhagen: University of Copenhagen; 2008.

10. Dumitrescu RG, Cotarla I. Understanding breast cancer risk - where do we stand in 2005? J Cell Mol Med. 2005;9(1):208-21.

11. Mitrunen K, Hirvonen A. Molecular epidemiology of sporadic breast cancer. The role of polymorphic genes involved in oestrogen biosynthesis and metabolism. Mutat Res. 2003;544(1):9-41. 
12. Rinaldi S, Peeters PH, Bezemer ID, Dossus L, Biessy C, Sacerdote C, Berrino F, Panico S, Palli D, Tumino R, Khaw KT, Bingham S, Allen NE, Key T, Jensen MK, Overvad K, Olsen A, Tjonneland A, Amiano P, Ardanaz E, Agudo A, Martinez-Garcia C, Quiros JR, Tormo MJ, Nagel G, Linseisen J, Boeing $H$, Schulz M, Grobbee DE, Bueno-de-Mesquita HB, Koliva M, Kyriazi G, Thrichopoulou A, Boutron-Ruault MC, Clavel-Chapelon F, Ferrari P, Slimani N, Saracci R, Riboli E, Kaaks R. Relationship of alcohol intake and sex steroid concentrations in blood in pre- and post-menopausal women: the European Prospective Investigation into Cancer and Nutrition. Cancer Causes Control. 2006;17(8):1033-43.

13. Onland-Moret NC, Peeters PH, van der Schouw YT, Grobbee DE, Van Gils CH. Alcohol and endogenous sex steroid levels in postmenopausal women: a crosssectional study. J Clin Endocrinol Metab. 2005;90(0021-972; 0021-972; 3):1414-9.

14. Hankinson SE, Willett WC, Manson JE, Hunter DJ, Colditz GA, Stampfer MJ, Longcope C, Speizer FE. Alcohol, height, and adiposity in relation to estrogen and prolactin levels in postmenopausal women. J Natl Cancer Inst. 1995:87(17):1297-302.

15. Muti $P$, Trevisan M, Micheli A, Krogh V, Bolelli G, Sciajno R, Schunemann HJ, Berrino F. Alcohol consumption and total estradiol in premenopausal women. Cancer Epidemiol Biomarkers Prev. 1998;7(3):189-93.

16. Coutelle C, Hohn B, Benesova M, Oneta CM, Quattrochi P, Roth HJ, SchmidtGayk H, Schneeweiss A, Bastert G, Seitz HK. Risk factors in alcohol associated breast cancer: alcohol dehydrogenase polymorphism and estrogens. Int J Oncol. 2004;25(4):1127-32

17. Dorgan JF, Baer DJ, Albert PS, Judd JT, Brown ED, Corle DK, Campbell WS, Hartman TJ, Tejpar AA, Clevidence BA, Giffen CA, Chandler DW, Stanczyk FZ, Taylor PR. Serum hormones and the alcohol-breast cancer association in postmenopausal women. J Natl Cancer Inst. 2001;93(9):710-5.

18. Reichman ME, Judd JT, Longcope C, Schatzkin A, Clevidence BA, Nair PP, Campbell WS, Taylor PR. Effects of alcohol consumption on plasma and urinary hormone concentrations in premenopausal women. J Natl Cancer Inst. 1993;85(9):722-7.

19. Ginsburg ES, Walsh BW, Gao X, Gleason RE, Feltmate C, Barbieri RL. The effect of acute ethanol ingestion on estrogen levels in postmenopausal women using transdermal estradiol. J Soc Gynecol Investig. 1995;2(1):26-9.

20. Ginsburg ES, Mello NK, Mendelson JH, Barbieri RL, Teoh SK, Rothman M, Gao X, Sholar JW. Effects of alcohol ingestion on estrogens in postmenopausal women. JAMA. 1996;276(21):1747-51.

21. Teoh SK, Mendelson JH, Mello NK, Skupny A, Ellingboe J. Alcohol effects on hCG-stimulated gonadal hormones in women. J Pharmacol Exp Ther. 1990;254(2):407-11.

22. Mendelson JH, Lukas SE, Mello NK, Amass L, Ellingboe J, Skupny A. Acute alcohol effects on plasma estradiol levels in women. Psychopharmacology (Berl). 1988;94(4):464-7

23. Sarkola T, Makisalo H, Fukunaga T, Eriksson CJ. Acute effect of alcohol on estradiol, estrone, progesterone, prolactin, cortisol, and luteinizing hormone in premenopausal women. Alcohol Clin Exp Res. 1999;23(6):976-82.

24. Gavaler JS, Deal SR, Van Thiel DH, Arria A, Allan MJ. Alcohol and estrogen levels in postmenopausal women: the spectrum of effect. Alcohol Clin Exp Res. 1993;17(4):786-90.

25. Gavaler JS, Love K, Van TD, Farholt S, Gluud C, Monteiro E, Galvao-Teles A Ortega TC, Cuervas-Mons V. An international study of the relationship between alcohol consumption and postmenopausal estradiol levels. Alcohol Alcohol Suppl. 1991;1:327-30.

26. Li Cl, Chlebowski RT, Freiberg M, Johnson KC, Kuller L, Lane D, Lessin L, O'Sullivan MJ, Wactawski-Wende J, Yasmeen S, Prentice R. Alcohol consumption and risk of postmenopausal breast cancer by subtype: the women's health initiative observational study. J Natl Cancer Inst. 2010; 102(18):1422-31.

27. Purohit V. Can alcohol promote aromatization of androgens to estrogens? A review. Alcohol. 2000;22(3):123-7.

28. Etique N, Chardard D, Chesnel A, Merlin JL, Flament S, Grillier-Vuissoz I. Ethanol stimulates proliferation, ERalpha and aromatase expression in MCF-7 human breast cancer cells. Int J Mol Med. 2004;13(1):149-55.

29. Vogel U, Christensen J, Nexo BA, Wallin H, Friis S, Tjonneland A. Peroxisome proliferator-activated corrected] receptor-gamma2 corrected] Pro12Ala, interaction with alcohol intake and NSAID use, in relation to risk of breast cancer in a prospective study of Danes. Carcinogenesis. 2007;28(2):427-34.

30. Petersen RK, Larsen SB, Jensen DM, Christensen J, Olsen A, Loft S, Nellemann C, Overvad K, Kristiansen K, Tjonneland A, Vogel U. PPARgamma-PGC-1alpha activity is determinant of alcohol related breast cancer. Cancer Lett. 2012;315(1):59-68.
31. Meirhaeghe A, Amouyel P. Impact of genetic variation of PPARgamma in humans. Mol Genet Metab. 2004:83(1-2):93-102.

32. Deeb SS, Fajas L, Nemoto M, Pihlajamaki J, Mykkanen L, Kuusisto J, Laakso M, Fujimoto W, Auwerx J. A Pro12Ala substitution in PPARgamma2 associated with decreased receptor activity, lower body mass index and improved insulin sensitivity. Nat Genet. 1998;20(3):284-7.

33. Siiteri PK. Adipose tissue as a source of hormones. Am J Clin Nutr. 1987; 45(1):277-82.

34. Monteiro R, Soares R, Guerreiro S, Pestana D, Calhau C, Azevedo I. Red wine increases adipose tissue aromatase expression and regulates body weight and adipocyte size. Nutrition. 2009;25(6):699-705.

35. Fan W, Yanase T, Morinaga H, Mu YM, Nomura M, Okabe T, Goto K, Harada N, Nawata $\mathrm{H}$. Activation of peroxisome proliferator-activated receptor-gamma and retinoid $\mathrm{X}$ receptor inhibits aromatase transcription via nuclear factor-kappaB. Endocrinology. 2005;146(1):85-92.

36. Rubin GL, Zhao Y, Kalus AM, Simpson ER. Peroxisome proliferator-activated receptor gamma ligands inhibit estrogen biosynthesis in human breast adipose tissue: possible implications for breast cancer therapy. Cancer Res. 2000:60(6):1604-8.

37. Chen D, Reierstad S, Lu M, Lin Z, Ishikawa H, Bulun SE. Regulation of breast cancer-associated aromatase promoters. Cancer Lett. 2009;273(1):15-27.

38. Tegeder I, Pfeilschifter J, Geisslinger G. Cyclooxygenase-independent actions of cyclooxygenase inhibitors. FASEB J. 2001;15(12):2057-72.

39. Kristensen DM, Hass U, Lesne L, Lottrup G, Jacobsen PR, Desdoits-Lethimonier C, Boberg J, Petersen JH, Toppari J, Jensen TK, Brunak S, Skakkebaek NE, Nellemann C, Main KM, Jegou B, Leffers $\mathrm{H}$. Intrauterine exposure to mild analgesics is a risk factor for development of male reproductive disorders in human and rat. Hum Reprod. 2011;26(1):235-44.

40. Marques-Pinto A, Carvalho D. Human infertility: are endocrine disruptors to blame? Endocr Connect. 2013;2(3):R15-29.

41. Takkouche B, Regueira-Mendez C, Etminan M. Breast cancer and use of nonsteroidal anti-inflammatory drugs: a meta-analysis. J Natl Cancer Inst. 2008;100(20):1439-47.

42. Friis S, Thomassen L, Sorensen HT, Tjonneland A, Overvad K, Cronin-Fenton DP, Vogel U, McLaughlin JK, Blot WJ, Olsen JH. Nonsteroidal anti-inflammatory drug use and breast cancer risk: a Danish cohort study. Eur J Cancer Prev. 2008;17(2):88-96

43. Meplan C, Dragsted LO, Ravn-Haren G, Tjonneland A, Vogel U, Hesketh J. Association between polymorphisms in glutathione peroxidase and selenoprotein P genes, glutathione peroxidase activity, HRT use and breast cancer risk. PLoS One. 2013;8(9):e73316.

44. Mellemkjaer L, Christensen J, Frederiksen K, Olsen A, Bennett P. Association of body composition measures and endogenous sex-steroid hormones among postmenopausal women. Open Obes J. 2011;3:51-5.

45. Tjonneland A, Christensen J, Thomsen BL, Olsen A, Overvad K, Ewertz M, Mellemkjaer L. Hormone replacement therapy in relation to breast carcinoma incidence rate ratios: a prospective Danish cohort study. Cancer. 2004;100(0008-543; 0008-543; 11):2328-37.

46. Tjonneland A, Christensen J, Thomsen BL, Olsen A, Stripp C, Overvad K, Olsen JH. Lifetime alcohol consumption and postmenopausal breast cancer rate in Denmark: a prospective cohort study. J Nutr. 2004;134(1):173-8.

47. Wagner JG, Albert KS, Szpunar GJ, Lockwood GF. Pharmacokinetics of ibuprofen in man IV: absorption and disposition. J Pharmacokinet Biopharm. 1984;12(4):381-99.

48. Davies NM. Clinical pharmacokinetics of ibuprofen. The first 30 years. Clin Pharmacokinet. 1998;34(2):101-54.

49. Miller SA, Dykes DD, Polesky HF. A simple salting out procedure for extracting DNA from human nucleated cells. Nucleic Acids Res. 1988;16(3):1215.

50. International HapMap Consortium. The International HapMap Project. Nature. 2003:426(6968):789-96.

51. Barrett JC, Fry B, Maller J, Daly MJ. Haploview: analysis and visualization of LD and haplotype maps. Bioinformatics. 2005;21(2):263-5.

52. Riancho JA, Valero C, Naranjo A, Morales DJ, Sanudo C, Zarrabeitia MT. Identification of an aromatase haplotype that is associated with gene expression and postmenopausal osteoporosis. J Clin Endocrinol Metab. 2007:92(0021-972; 0021-972; 2):660-5.

53. Beckmann L, Husing A, Setiawan WW, Amiano P, Clavel-Chapelon F, Chanock SJ, Cox DG, Diver R, Dossus L, Feigelson HS, Haiman C, Hallmans G, Hayes RB, Henderson BE, Hoover RN, Hunter DJ, Khaw K, Kolonel LN, Kraft P, Lund E, Le ML, Peeters PH, Riboli E, Stram D, Thomas G, Thun MJ, Tumino R, Trichopoulos D, Vogel U, Willett WC, Yeager M, Ziegler R, Hankinson SE, 
Kaaks R. Comprehensive analysis of hormone and genetic variation in 36 genes related to steroid hormone metabolism in pre- and postmenopausal women from the breast and prostate cancer cohort consortium (BPC3). J Clin Endocrinol Metab. 2011;96(0021-972; 2):E360-7.

54. Kristensen VN, Harada N, Yoshimura N, Haraldsen E, Lonning PE, Erikstein B, Karesen R, Kristensen T, Borresen-Dale AL. Genetic variants of CYP19 (aromatase) and breast cancer risk. Oncogene. 2000;19(10):1329-33.

55. Dunning AM, Dowsett M, Healey CS, Tee L, Luben RN, Folkerd E, Novik KL, Kelemen L, Ogata S, Pharoah PD, Easton DF, Day NE, Ponder BA. Polymorphisms associated with circulating sex hormone levels in postmenopausal women. J Natl Cancer Inst. 2004;96(12):936-45.

56. Haiman CA, Dossus L, Setiawan WW, Stram DO, Dunning AM, Thomas G, Thun MJ, Albanes D, Altshuler D, Ardanaz E, Boeing H, Buring J, Burtt N, Calle EE, Chanock S, Clavel-Chapelon F, Colditz GA, Cox DG, Feigelson HS, Hankinson SE, Hayes RB, Henderson BE, Hirschhorn JN, Hoover R, Hunter DJ, Kaaks R, Kolonel LN, Le ML, Lenner P, Lund E, Panico S, Peeters PH, Pike MC, Riboli E, Tjonneland A, Travis R, Trichopoulos D, Wacholder S, Ziegler RG. Genetic variation at the CYP19A1 locus predicts circulating estrogen levels but not breast cancer risk in postmenopausal women. Cancer Res. 2007:67(5):1893-7.

57. Yoshimoto N, Nishiyama T, Toyama T, Takahashi S, Shiraki N, Sugiura H, Endo $Y$, Iwasa M, Fujii Y, Yamashita H. Genetic and environmental predictors, endogenous hormones and growth factors, and risk of estrogen receptorpositive breast cancer in Japanese women. Cancer Sci. 2011;102(11):2065-72.

58. Zhang L, Gu L, Qian B, Hao X, Zhang W, Wei Q, Chen K. Association of genetic polymorphisms of ER-alpha and the estradiol-synthesizing enzyme genes CYP17 and CYP19 with breast cancer risk in Chinese women. Breast Cancer Res Treat. 2009;114(2):327-38.

59. Fasching PA, Loehberg CR, Strissel PL, Lux MP, Bani MR, Schrauder M, Geiler S, Ringleff K, Oeser S, Weihbrecht S, Schulz-Wendtland R, Hartmann A, Beckmann MW, Strick R. Single nucleotide polymorphisms of the aromatase gene (CYP19A1), HER2/neu status, and prognosis in breast cancer patients. Breast Cancer Res Treat. 2008;112(1):89-98.

60. Petry CJ, Ong KK, Michelmore KF, Artigas S, Wingate DL, Balen AH, de Zegher F, Ibanez L, Dunger DB. Association of aromatase (CYP 19) gene variation with features of hyperandrogenism in two populations of young women. Hum Reprod. 2005;20(7):1837-43.

61. Chen Z, Tao S, Gao Y, Zhang J, Hu Y, Mo L, Kim ST, Yang X, Tan A, Zhang H, Qin X, Li L, Wu Y, Zhang S, Zheng SL, Xu J, Mo Z, Sun J. Genome-wide association study of sex hormones, gonadotropins and sex hormonebinding protein in Chinese men. J Med Genet. 2013:50(12):794-801.

62. Prentice RL, Kalbfleisch JD, Peterson Jr AV, Flournoy N, Farewell VT, Breslow NE. The analysis of failure times in the presence of competing risks. Biometrics. 1978;34(0006-341; 0006-341; 4):541-54.

63. Vogel U, Christensen J, Wallin H, Friis S, Nexo BA, Tjonneland A. Polymorphisms in COX-2, NSAID use and risk of basal cell carcinoma in a prospective study of Danes. Mutat Res. 2007;617(1-2):138-46.

64. Andersen V, Holst R, Kopp TI, Tjonneland A, Vogel U. Interactions between Diet, Lifestyle and IL10, IL1B, and PTGS2/COX-2 Gene Polymorphisms in Relation to Risk of Colorectal Cancer in a Prospective Danish Case-Cohort Study. PLoS One. 2013;8(10):e78366.

65. Andersen V, Ostergaard M, Christensen J, Overvad K, Tjonneland A, Vogel U. Polymorphisms in the xenobiotic transporter Multidrug Resistance 1 (MDR1) and interaction with meat intake in relation to risk of colorectal cancer in a Danish prospective case-cohort study. BMC Cancer. 2009;9:407.

66. Straume AH, Knappskog S, Lonning PE. Effect of CYP19 rs6493497 and rs7176005 haplotype status on in vivo aromatase transcription, plasma and tissue estrogen levels in postmenopausal women. J Steroid Biochem Mol Biol. 2012;128(1-2):69-75.

67. Dunning AM, Healey CS, Pharoah PD, Teare MD, Ponder BA, Easton DF. A systematic review of genetic polymorphisms and breast cancer risk. Cancer Epidemiol Biomarkers Prev. 1999:8(10):843-54.

68. Healey CS, Dunning AM, Durocher F, Teare D, Pharoah PD, Luben RN, Easton DF, Ponder BA. Polymorphisms in the human aromatase cytochrome P450 gene (CYP19) and breast cancer risk. Carcinogenesis. 2000;21(2):189-93.

69. Ma X, Qi X, Chen C, Lin H, Xiong H, Li Y, Jiang J. Association between CYP19 polymorphisms and breast cancer risk: results from 10,592 cases and 11,720 controls. Breast Cancer Res Treat. 2010;122(2):495-501.

70. Sieri S, Agudo A, Kesse E, Klipstein-Grobusch K, San-Jose B, Welch AA, Krogh V, Luben R, Allen N, Overvad K, Tjonneland A, Clavel-Chapelon F, Thiebaut A, Miller AB, Boeing H, Kolyva M, Saieva C, Celentano E, Ocke MC, Peeters $\mathrm{PH}$, Brustad M, Kumle M, Dorronsoro M, Fernandez FA, Mattisson I,
Weinehall L, Riboli E, Slimani N. Patterns of alcohol consumption in 10 European countries participating in the European Prospective Investigation into Cancer and Nutrition (EPIC) project. Public Health Nutr. 2002;5(6):1287-96.

71. Friis S, Poulsen AH, Sorensen HT, Tjonneland A, Overvad K, Vogel U, McLaughlin JK, Blot WJ, Olsen JH. Aspirin and other non-steroidal antiinflammatory drugs and risk of colorectal cancer: a Danish cohort study. Cancer Causes Control. 2009;20(5):731-40

72. Friis S, Riis AH, Erichsen R, Baron JA, Sorensen HT. Low-Dose Aspirin or Nonsteroidal Anti-inflammatory Drug Use and Colorectal Cancer Risk: A Population-Based, Case-control Study. Ann Intern Med. 2015;163(5):347-55.

73. Ginsburg ES, Walsh BW, Shea BF, Gao X, Gleason RE, Feltmate C, Barbieri RL. Effect of acute ethanol ingestion on prolactin in menopausal women using estradiol replacement. Gynecol Obstet Invest. 1995;39(1):47-9.

74. Nagata C, Kabuto M, Takatsuka N, Shimizu H. Associations of alcohol, height, and reproductive factors with serum hormone concentrations in postmenopausal Japanese women. Steroid hormones in Japanese postmenopausal women. Breast Cancer Res Treat. 1997:44(3):235-41.

75. Madigan MP, Troisi R, Potischman N, Dorgan JF, Brinton LA, Hoover RN. Serum hormone levels in relation to reproductive and lifestyle factors in postmenopausal women (United States). Cancer Causes Control. 1998;9(2):199-207.

76. Endogenous Hormones and Breast Cancer Collaborative Group, Key TJ, Appleby PN, Reeves GK, Roddam AW, Helzlsouer KJ, Alberg AJ, Rollison DE, Dorgan JF, Brinton LA, Overvad K, Kaaks R, Trichopoulou A, Clavel-Chapelon F, Panico S, Duell EJ, Peeters PH, Rinaldi S, Fentiman IS, Dowsett M, Manjer J, Lenner P, Hallmans G, Baglietto L, English DR, Giles GG, Hopper JL, Severi G, Morris HA, Hankinson SE, Tworoger SS, Koenig K, Zeleniuch-Jacquotte A, Arslan AA, Toniolo P, Shore RE, Krogh V, Micheli A, Berrino F, Barrett-Connor E, Laughlin GA, Kabuto M, Akiba S, Stevens RG, Neriishi K, Land CE, Cauley JA, Lui LY, Cummings SR, Gunter MJ, Rohan TE, Strickler HD. Circulating sex hormones and breast cancer risk factors in postmenopausal women: reanalysis of 13 studies. Br J Cancer. 2011;105(5):709-22.

77. Wu F, Ames R, Evans MC, France JT, Reid IR. Determinants of sex hormonebinding globulin in normal postmenopausal women. Clin Endocrinol (Oxf). 2001;54(1):81-7.

78. Rachdaoui N, Sarkar DK. Effects of alcohol on the endocrine system. Endocrinol Metab Clin North Am. 2013:42(3):593-615.

79. Sarkola T, Ahola L, von Der PB, Eriksson CJ. Lack of effect of alcohol on ethinylestradiol in premenopausal women. Contraception. 2001;63(1):19-23.

80. Sarkola T, Fukunaga T, Makisalo H, Peter Eriksson CJ. Acute effect of alcohol on androgens in premenopausal women. Alcohol Alcohol. 2000;35(1):84-90.

81. Mendelson JH, Mello NK, Ellingboe J. Acute alcohol intake and pituitary gonadal hormones in normal human females. J Pharmacol Exp Ther. 1981;218(1):23-6.

82. Stanczyk FZ, Clarke NJ. Advantages and challenges of mass spectrometry assays for steroid hormones. J Steroid Biochem Mol Biol. 2010;121(3-5):491-5.

83. Blair IA. Analysis of estrogens in serum and plasma from postmenopausal women: past present, and future. Steroids. 2010;75(4-5):297-306.

\section{Submit your next manuscript to BioMed Central and we will help you at every step:}

- We accept pre-submission inquiries

- Our selector tool helps you to find the most relevant journal

- We provide round the clock customer support

- Convenient online submission

- Thorough peer review

- Inclusion in PubMed and all major indexing services

- Maximum visibility for your research

Submit your manuscript at www.biomedcentral.com/submit
Ciomed Central 